\title{
O novo currículo do Curso de Licenciatura em Física do CEFET/RJ, Campus Petrópolis ${ }^{+*}$
}

\author{
Daniel Neves Micha ${ }^{1}$ \\ Marcilia Elis Barcellos ${ }^{1}$ \\ Glauco dos Santos Ferreira da Silva ${ }^{1}$ \\ Elisabeth Gonçalves de Souzal \\ Marcos Corrêa da Silva ${ }^{1}$ \\ Eduardo Teles da Silva ${ }^{l}$ \\ Demerson Nunes Gonçalves ${ }^{1}$ \\ Centro Federal de Educação Tecnológica Celso Suckow da Fonseca \\ Campus Petrópolis \\ Petrópolis - RJ
}

\section{Resumo}

A Resolução 02/2015 do Conselho Pleno do Conselho Nacional de Educação estabeleceu novas Diretrizes Curriculares Nacionais (DCN) para os cursos de formação inicial e continuada de professores, onde se incluem os cursos de licenciatura. Nesse trabalho, apresentamos o relato da reformulação curricular para um curso de licenciatura em física na modalidade presencial (noturna) em adequação com as novas DCN. Apesar da imposição da reestruturação de todos os cursos a nível nacional em até dois anos, não foi esse o principal motivador de nossa revisão curricular, haja visto que o processo já havia sido iniciado com a instauração de uma Comissão de Reformulação no ano anterior à publicação da resolução. Dessa forma, apresentamos, neste trabalho, as mudanças realizadas para cumprimento das exigências legais, bem como a discussão do processo reflexivo e autocrítico vivido na elaboração desse currículo, o qual se baseia na experiência acumulada pelos autores desse trabalho, professores, alunos e funcionários, ao longo dos oito anos

\footnotetext{
+ The New Curriculum of the CEFET/RJ (Petrópolis) Undergraduate Physics Teacher Education Program

* Recebido: março de 2018. Aceito: junho de 2018.

${ }^{1}$ E-mails: daniel.micha@cefet-rj.br; marcilia12@hotmail.com; glauco.silva@cefet-rj.br; elisabethsouza.cefetrj@gmail.com; marcos.fismarc@gmail.com; ude01x@gmail.com; DEMERSON.GONCALVES@gmail.com
} 
de oferta do Curso de Licenciatura em Física do CEFET/RJ campus Petrópolis. Além das análises reflexivas, descrevemos também às análises quantitativas de evasão e retenção ao longo da oferta do curso que justificaram as mudanças propostas.

Palavras-chave: Reformulação Curricular; Integração Teoria-Prática; Licenciatura em Física.

\begin{abstract}
The Resolution 02/2015 of the Brazilian Education Main Council has established the new National Curriculum Guidelines for the initial and continuing teacher education in which physics teacher education programs are included. In this study, we report the description on the curriculum reformulation process that was carried out to adequate a nightly presential physics teacher education program to the new guidelines. Despite of the compromise to implement the reformulations within two years imposed by the Resolution, this was not the main reason for the curriculum revision. The process had already been initiated with a committee established in the year before of the new guidelines enacting. In this way, we show, in this study, changes realized in observance of the legal requirements as well as an interesting discussion of the reflexive and self-critical process that led to the new curriculum. It is important to note that the reformulation process has taken into account the experience over the eight years of existence of the program in which several participants contributed such as the authors of this paper, other professors, undergraduate students, and CEFET's employees. Beyond the reflexive analysis, we also describe quantitative data on the college dropout and failure in the physics teacher education program lifetime that justify the changes done.
\end{abstract}

Keywords: Curricular Reformulation; Theory-Practice Integration; Physics Teacher Education.

\title{
I. Introdução
}

Neste trabalho, apresentamos o processo de reformulação curricular realizado entre 2014 e 2016 no Curso de Licenciatura em Física do CEFET/RJ campus Petrópolis e as mudanças implementadas na nova versão, já em vigor desde o início de 2017. 
Além da exigência legal imposta pela Resolução CNE/CP 02/2015, que veio posteriormente ao início do processo de revisão curricular, o processo foi fruto de reflexões decorrentes da autoavaliação dos professores sobre o próprio curso colhidas ao longo dos seus oito anos de oferta e da avaliação de reconhecimento do curso pelo Ministério da Educação (MEC), realizada em 2014.

O texto busca mostrar os caminhos trilhados nessa construção, identificando os desafios e as contradições enfrentados pela Comissão de Reformulação (autores deste artigo) do currículo ao tentar pensar soluções que conciliassem as demandas dos diversos atores que participam da arena da formação docente: necessidades apontadas pelos licenciandos, pelos professores do curso e pelo MEC, através das exigências advindas da política de formação docente e do resultado da avaliação do curso feita pelos agentes desse ministério. O que temos é uma síntese desse processo que permite a sua ressignificação em outros contextos de formação.

Iniciamos por uma descrição do currículo na sua versão anterior contando muito brevemente sua história. Na sequência do texto são apontados os motivadores da mudança curricular a partir do levantamento dos problemas vivenciados e da reflexão sobre eles. Por fim, apresentamos o novo currículo justificando as mudanças implementadas e como elas pretendem responder a problematização inicial.

\section{I.10 Curso de Licenciatura em Física do CEFET/RJ campus Petrópolis}

No contexto do programa de expansão da rede federal de educação tecnológica, surge o Curso de Licenciatura em Física do CEFET/RJ campus Petrópolis, objeto da análise desse trabalho, tendo sua primeira turma ingressado em agosto de 2008. O Projeto Pedagógico do Curso (PPC) atendeu a todas as legislações vigentes, com a distribuição da carga horária de Conteúdos Curriculares Científicos e Culturais (CCCC), de Estágio Supervisionado (ES) e de Prática como Componente Curricular (PCC), além das horas de atividades complementares (AACC).

O primeiro PPC do curso foi fruto de um projeto piloto formulado por professores da instituição à época. Contudo, esses professores atuavam em áreas e segmentos de ensino que não tinham, necessariamente, relação direta com cursos de licenciatura. Após sua versão original e do início da oferta do curso, houve modificações da matriz curricular pelo próprio corpo docente formado para atuar no curso de licenciatura em física. A última versão da matriz curricular desse curso, a qual passaremos a chamar de Currículo Antigo, é apresentada no Anexo 2.

Como um todo, o Currículo Antigo se estruturou de modo bastante convencional, reproduzindo o principal problema do modelo $3+1$, que é a falta de relação entre conhecimentos específicos da área e conhecimentos pedagógicos (GATTI, 2010).

No Currículo Antigo, no que concerne ao conteúdo específico, as disciplinas básicas de Matemática, tais como Cálculo Diferencial (1, 2 e 3), Geometria Analítica, Vetores, Álge- 
bra Linear e Estatística, e as de Física Básica, tais como Mecânica Clássica, Física Térmica, Eletromagnetismo Básico e Física Ondulatória, eram oferecidas na primeira metade do curso. Os conteúdos mais avançados de Física, tais como Física Moderna (1 e 2), Mecânica Estatística, Mecânica Analítica, Tópicos de Eletromagnetismo e Tópicos Aplicados de Física Contemporânea, eram apresentados nos últimos anos. A disciplina de Introdução à Física, oferecida no primeiro período, destoava das demais, tradicionalmente presentes nos currículos de cursos de licenciatura em física, apresentando a física numa perspectiva panorâmica e motivadora (BARCELLOS et al., 2010).

As disciplinas pedagógicas, tais como Fundamentos da Educação, Didática Básica, Planejamento e Avaliação da Aprendizagem, Políticas Educacionais e Formação de Professores no Brasil e Psicologia Aplicada à Educação, também bastante convencionais, estavam distribuídas ao longo dos três primeiros anos do curso.

A articulação entre os conteúdos pedagógicos e os específicos ficava por conta das 405 horas de PCC distribuídas, dentre outras, nas Oficinas de Projetos de Ensino (OPE) das grandes áreas da Física (Mecânica, Física Térmica, Eletromagnetismo, Física Ondulatória e Física Moderna). Outras disciplinas de caráter interdisciplinar, tais como Química Geral, Comunicação e Linguagem, Introdução à Ciência da Computação e LIBRAS, estavam distribuídas ao longo do curso e complementavam a carga horária de CCCC.

O Estágio Supervisionado (ES) era cumprido nas duas últimas disciplinas de OPE (Eletromagnetismo e Física Ondulatória e Moderna) e nas disciplinas de Prática de Ensino e Estágio Supervisionado, a partir do $5^{\circ}$ período.

A conclusão do curso e a formatura se davam mediante o cumprimento da carga horária de disciplinas obrigatórias, no total de 2.355 horas, disciplinas optativas/eletivas, no total de 165 horas, ES, no total de 405 horas, das atividades complementares (participação em simpósios, congressos, palestras, cursos, dentre outros), no total de 240 horas, e da defesa da monografia como trabalho de conclusão de curso.

\section{A necessidade da reformulação}

\section{II.1 Autoavaliação: alguns problemas vivenciados no contexto do Currículo Antigo}

A primeira turma do Curso de Licenciatura em Física do CEFET/RJ campus Petrópolis, composta de 28 alunos, ingressou na instituição junto à inauguração do curso no segundo semestre de 2008 (2008/2). Desde então, o curso vem oferecendo duas entradas anuais com 40 vagas cada. Do total das 680 vagas abertas entre 2008/2 e 2016/2, data da última entrada de alunos no Currículo Antigo, apenas 391 foram preenchidas. De todos esses alunos, apenas 142 mantiveram alguma relação com o curso até 2016/2, sejam alunos ativos (119) ou egressos (23). 
A Tabela 1 resume os dados estatísticos relacionados aos alunos ingressantes, egressos e ativos no Currículo Antigo até 2016/2 por semestre de ingresso. Além disso, é informado também a média de tempo (em anos) que os alunos egressos levaram para concluir o curso.

Tabela 1 - Dados estatísticos dos alunos ingressantes, egressos e ativos do Currículo Antigo do Curso de Licenciatura em Física do CEFET/RJ entre 2008/2 e 2016/2.

\begin{tabular}{|c|c|c|c|c|}
\hline Ano/Semestre & Ingressantes & $\begin{array}{c}\text { Egressos até } \\
2016 / 2\end{array}$ & $\begin{array}{l}\text { Média de anos } \\
\text { para formação }\end{array}$ & $\begin{array}{l}\text { Alunos ativos ao } \\
\text { final de } 2016 / 2\end{array}$ \\
\hline $2008 / 2$ & 28 & 2 & 8,0 & 0 \\
\hline $2009 / 1$ & 19 & 7 & 6,5 & 2 \\
\hline $2009 / 2$ & 27 & 3 & 5,2 & 2 \\
\hline $2010 / 1$ & 25 & 4 & 4,3 & 0 \\
\hline $2010 / 2$ & 19 & 2 & 5,25 & 1 \\
\hline $2011 / 1$ & 31 & 2 & 5,7 & 1 \\
\hline $2011 / 2$ & 17 & 0 & - & 1 \\
\hline $2012 / 1$ & 25 & 1 & 4,5 & 3 \\
\hline $2012 / 2$ & 14 & 1 & 4,0 & 3 \\
\hline $2013 / 1$ & 30 & 1 & 4,0 & 9 \\
\hline $2013 / 2$ & 12 & 0 & - & 5 \\
\hline $2014 / 1$ & 24 & 0 & - & 8 \\
\hline $2014 / 2$ & 14 & 0 & - & 4 \\
\hline $2015 / 1$ & 25 & 0 & - & 16 \\
\hline $2015 / 2$ & 31 & 0 & - & 19 \\
\hline $2016 / 1$ & 30 & 0 & - & 26 \\
\hline $2016 / 2$ & 20 & 0 & - & 19 \\
\hline Total & 391 & 23 & 5,65 & 119 \\
\hline
\end{tabular}

A primeira colação de grau ocorreu em 2012/2, com apenas um aluno, ingressante da turma em 2009/1. Dessa mesma turma, dos 24 ingressantes, mais 6 alunos colaram grau em outros semestres em uma média de 6,5 anos. No entanto, da primeira turma de 2008/2 dos 28 ingressantes, apenas 2 alunos obtiveram êxito no curso em uma média de 8,0 anos. Além disso, todos os outros alunos evadiram do curso.

Da última coluna da Tabela 1, é possível observar os alunos ativos no curso em 2016/2. Dos 205 ingressantes até 2012/2, apenas 13 tinham matrícula ativa e 22 alunos se 
formaram, totalizando 34 alunos que ainda tinham relação com o curso. Isso significa uma evasão de cerca de $83 \%$ para os alunos ingressantes nos 4 primeiros anos do curso. Dos 186 ingressantes nos 4 anos seguintes, entre 2013/1 e 2016/2, 106 alunos ainda se mantém ligados ao curso. A taxa de evasão para esse período é menor, de cerca de $42 \%$. A evasão total ao longo dos 8 anos analisados é de 63\%. Apesar de bastante alta, essas taxas de evasão não são incomuns para cursos de Física no Brasil (BARROSO; FALCÃO, 2005; ATAIDE et al., 2007; JUNIOR; SOUZA, 2007; ALMEIDA; SCHIMIGUEL, 2011; SOUZA et al., 2009; SILVA; KAWAMURA, 2011; UIBSON et al., 2014).

Uma questão que se mostrou importante para compreender o fator do elevado tempo de conclusão do curso foi a observação de uma prática recorrente no percurso curricular dos alunos que é a matrícula em disciplinas de períodos mais avançados que não possuíam prérequisitos, logo na primeira metade do curso.

A principal motivação para essa prática era a falsa impressão que o aluno tinha de estar avançando mais rápido no curso. Ou ainda, se sofressem alguma reprovação naquele semestre, acreditavam que ter cursado e sido aprovado em outras disciplinas de semestres mais avançados lhe daria a possibilidade de concluir o curso dentro do prazo de integralização mínimo.

Outra motivação era a fuga de um tipo específico de disciplina na qual o aluno sente mais dificuldade, para se matricular em outras consideradas mais fáceis e que não possuíam nenhum pré-requisito. Essa prática possibilitava os alunos escolhas que mais tarde se mostrariam equivocadas, configurando-se em uma das possíveis causas para o aumento do tempo de conclusão no curso.

Buscando maiores respostas para os altos índices de evasão do curso, realizamos estudos mais aprofundados para discutir as possíveis causas do problema. Ao analisarmos a quantidade de períodos cursados pelos alunos evadidos, conforme pode ser visualizado na Fig. 1, percebemos que a maioria abandona o curso nos períodos iniciais, com uma maior incidência no próprio período de ingresso. Essa análise é corroborada por outros estudos realizados com dados desse mesmo curso, como em Grizoni e Silva (2014), e também por estudos realizados em outros cursos como o trazido por Barroso e Falção (2005).

Para ajudar a compreender os possíveis motivos da alta evasão nos períodos iniciais, utilizamos dados que são coletados sistematicamente pela Seção de Articulação Pedagógica do campus, por meio de anamneses realizadas com os alunos ingressantes a cada semestre. Nesses conjuntos de questionários e entrevistas, informações importantes envolvendo questões socioeconômicas, familiares, os objetivos do aluno com a graduação, sua experiência pregressa, dentre outras, são coletadas.

Analisando as respostas dos ingressantes nessas anamneses, percebemos que o curso de licenciatura em Física não era a primeira opção para a maioria desses estudantes. A pouca oferta de cursos superiores públicos e gratuitos na cidade parece contribuir para esse quadro, composto de alunos locais desejosos de ingressar em outros cursos, tais como engenharias e 
bacharelados, e que buscam na licenciatura uma segunda ou terceira opção, muitas vezes encarada como temporária, até conseguirem algo que mais os satisfazem. Esse dado corrobora com estudo realizado por Almeida e Schimiguel (2011). Em tal pesquisa os autores apontam que a própria escolha pelo curso é um dos fatores mais ressaltados para justificar a evasão.

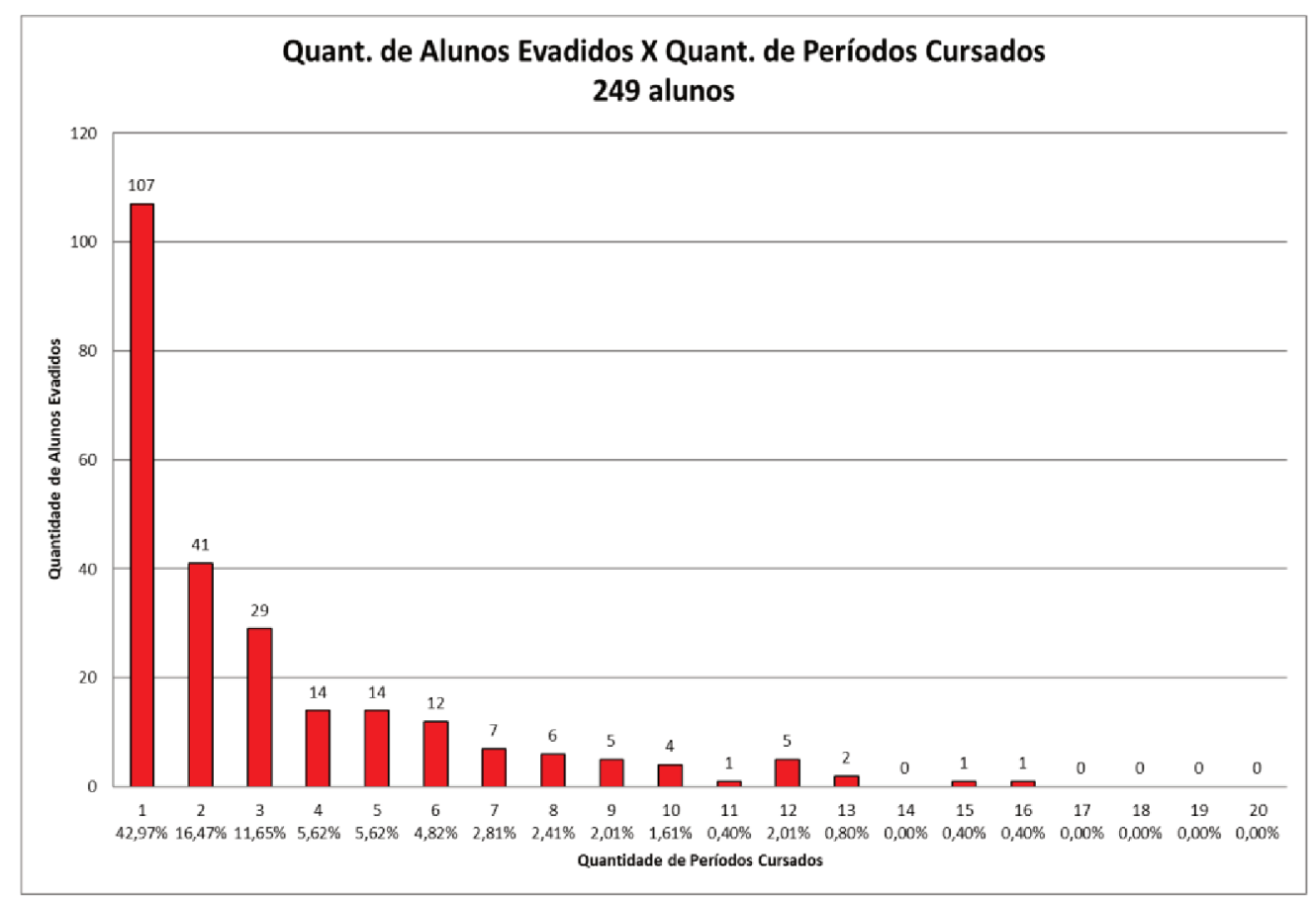

Fig. 1 - Análise de evasão por número de periodos cursados no Curso de Licenciatura em Física do campus Petrópolis do CEFET/RJ.

A falta de interesse por cursos de licenciatura, principalmente na área das ciências exatas, também é um fator importante, sendo esse problema uma realidade mundial (ARAÚJO; VIANNA, 2008). Para além das questões salariais dos docentes e da desvalorização social da figura do professor, as próprias condições de trabalho nas escolas, principalmente, públicas trazem inúmeros desafios aos professores com a diversidade sociocultural de seus alunos. A análise das anamneses corroboram dados trazido por Ataide et al. (2007) em relação à heterogêineidade dos alunos do curso de licenciatura em física.

Como apontado por Souza et al. (2009), os fatores que influenciam a evasão de alunos no curso pode ter ou não relação com a estrutura curricular e com a proposta do curso. Algumas justificativas podem ter cunho muito individual, porém outras apontam fatores mais institucionalizados.

Vários desses fatores nos remetem à prática docente levando aos cursos de formação de professores a necessidade de reflexão acerca das formas como se dão os processos de formação, sendo o currículo um dos elementos centrais para a ocorrência desses processos. A forma desinteressante como os conteúdos são apresentados, o estímulo a uma aprendizagem baseada em memória de fórmulas, a falta de conexão com as situações cotidianas dos alunos, 
a desconexão entre o currículo e a prática docente, dentre outras, são práticas de ensinoaprendizagem arraigadas que são replicadas durante o processo de formação do professor. Por esse motivo, a problemática deve ser enfrentada pelos professores do ensino superior e, desejavelmente, abordada também no currículo.

Para nos ajudar a avaliar o impacto da matriz curricular na evasão do curso, realizamos uma análise quantitativa do número de aprovações, reprovações por falta, reprovações por nota e trancamento de todas as disciplinas do curso ao longo de toda a oferta do Currículo Antigo. Como o nosso interesse aqui é avaliar a dificuldade enfrentada pelos alunos nas disciplinas, principalmente nos primeiros períodos, apresentamos na Tabela 2 os índices de reprovações por nota no curso entre 2008/2 e 2016/2. Os dados são apresentados em escala de cores para facilitar a visualização, onde cores mais claras, próximas ao verde, representam nenhuma ou pouca reprovação e cores mais escuras, próximas ao vermelho, representam maiores índices de reprovação.

Combinando os dados das anamneses com os da Tabela 2, percebe-se, de forma geral, dois perfis principais de alunos que permanecem no curso: aqueles que se identificam mais com a carreira científica, e portanto, tendem a ter melhores rendimentos nas disciplinas de Física e Matemática; e os que se identificam mais propriamente com a carreira docente e tendem a ter melhores rendimentos nas disciplinas pedagógicas e interdisciplinares. No entanto, não realizamos estudos específicos para melhor caracterizar o perfil dos estudantes que permanecem no curso, de tal forma, que estamos apenas fazendo uma inferência a partir de dados mais gerais.

Da Tabela 2, pode-se perceber que os maiores índices de reprovação estão nos dois primeiros períodos, especialmente, Cálculo Dif. e Integral (1 e 2), Vetores e Geometria Analítica e Mecânica Clássica. Esse fator parece contribuir para os altos índices de evasão nos dois primeiros períodos do curso. Com relação à dificuldade enfrentada pelos ingressantes nas disciplinas dos períodos iniciais, a narrativa dos professores era recorrente sobre a falta de base em Matemática e Física, e também sobre as sérias deficiências em leitura, escrita e hábitos de estudo inexistentes ou pouco efetivos.

Nessa análise é importante ressaltar a mudança no perfil dos alunos ingressantes na universidade, uma vez que atendemos atualmente a um público oriundo de camadas populares que antes não tinha acesso ao nível superior de ensino, bem como a nova perspectiva para educação básica após a Lei de Diretrizes e Bases (LDB) de 1996, em que o ensino médio deixa de ser uma etapa preparatória para o ensino superior. Barcellos et al. (2017) reforçam essa perspectiva ao afirmarem que

Pela lei, temos um ensino médio que deve preparar o aluno para o prosseguimento nos estudos, mas também é um nível obrigatório a toda uma classe de jovens que não tem aspirações nem acesso ao ensino superior. Isso em última análise relega ao próprio ensino médio regular o desafio de justificar-se em si mesmo, para além da vocação propedêutica (p. 128). 
Tabela 2 - Índices históricos de reprovação por notas nas disciplinas do Currículo Antigo do Curso de Licenciatura em Física do campus Petrópolis do CEFET/RJ entre 2008/2 e 2016/2.

\begin{tabular}{|c|c|c|c|c|c|c|c|c|c|c|c|c|c|c|c|c|c|c|}
\hline Disciplina & Perlodo & $2008 / 2$ & $2009 / 1$ & $2009 / 2$ & $2010 / 1$ & $2010 / 2$ & $2011 / 1$ & $2011 / 2$ & $2012 / 1$ & $2012 / 2$ & $2013 / 1$ & $2013 / 2$ & $2014 / 1$ & $2014 / 2$ & $2015 / 1$ & $2015 / 2$ & $2016 / 1$ & $2016 / 2$ \\
\hline CALCULO DFERENCAL E INTLGRALI & 1 & 0,55714 & 0,153946 & 0,47619 & 0,022727 & 0,521739 & 0049193 & 0,21975 & 0,179487 & 0,291607 & 0,2 & 0,304348. & 0,49313 & 0,34375 & 0,282051 & 0,372099 & 0,42 & 0,326097 \\
\hline 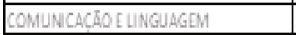 & 1 & 0,17257 & 0,097037 & 0,125 & 0 & 0 & 0 & 0 & 0,034483 & 0 & 0 & 0,230769 & 0,125 & 0,083913 & 0,103449 & 0,02857 & 0 & 0,03313 \\
\hline FUAD ANENTOS DA EOULACBO & 1 & 0 & 0 & 0 & 0,185195 & 0 & 0,013158 & 0 & 0 & 0 & 0 & 0 & 0 & 0,083331 & 0,21426 & 0,290123 & 0,25 & 0,347826 \\
\hline WTRODUCBOA AFILA & 1 & 0 & 0 & 0,035714 & 0,000966 & 0,022727 & 0,012321 & 0,59099 & 0 & 0 & 0 & 0,272727 & 70,006957 & 0 & 0,074074 & 0 & 0,258005 & 0,02655 \\
\hline WETORSS E GOOMLTRIA.ANALATICA & 1 & 0.5 & 0,359379 & 0,17777 & 0,041667 & 0,229167 & 0,0476 & 0,172414 & 0,216210 & 0,24 & 0,047619 & 0,191818 & 0,1875 & 0,208313 & 0,677419 & 0,091113 & 0,344262 & 0,3 \\
\hline CALCULO DIFERENCIAL E INTEGALAL II & 2 & & 0,2 & 0,191318 & 0,470598 & 0,389289 & 0,024412 & 0,62 & $0,2 \pi$ & 0,25 & 0,41176 & D,05FSE & 0 & 0,2 & 0,3 & 0,043478 & 0,714286 & 0,16129 \\
\hline DIDATICA BASICA & 2 & 0 & 0 & 0 & 0 & 0 & 0 & 0 & & 0 & 0 & 0 & 0 & 0,083393 & 0 & 0 & 0,071429 & 0,045455 \\
\hline INTROOUCSOOA A LIGEERA LINEAR & 2 & & 0,16660 & 0,142257 & 0,272727 & 0,3 & 0,181918 & 0,166606 & 0,071429 & 0,307642 & 0 & 0,394615 & 0,6 & 0,24 & 0 & 0,222222 & 0,42857 & 0,230769 \\
\hline LADORATORIO OE MECȦNICA CLLSSICA & 2 & & 0 & 0 & 0,105261 & 0 & 0,05824 & 0,23909 & 0 & 0 & 0 & 0,0025 & 0,4 & 0,22005 & 0,160667 & 0,125 & 0,36 & 0,290123 \\
\hline MECḊNICA CLLSSICA & 2 & & 0,230709 & 0,05262 & 0,6 & 0,33333 & 0047619 & 0,413793 & 0,473644 & 0,266667 & 0,451538 & 0,166657 & $70,0,904702$ & 0,351111 & 0,54545 & 0,424242 & 0,341469 & 0,25 \\
\hline CALCULO DIFERENCIAL E INTEGRAL III & 3 & & & 0 & 0,2 & 0,111111 & 0,071429 & 0,636364 & 0 & 0,333333 & 0,009091 & | 0,399899 & 0,25 & | 0,133393 & 0,307692 & 0 & $|0,363636|$ & 0,375 \\
\hline FLU DOSE EF SICA TERMICA & 3 & & & & 0 & 0,2 & 0,339393 & 0 & 0,25 & 0,272727 & 0,375 & 0,1 & 0,142857 & 0,25 & 0,369636 & $0,3636,36$ & 0,5 & 0,75 \\
\hline WETODOS MATLMATICOSI & 3 & & & 0 & 0,166667 & 0 & 0,2 & 0,625 & 0 & 0 & 0,153946 & 0,3 & 0,25 & 0,142257 & 0,166667 & 0,4 & 0,191918 & 0,25 \\
\hline 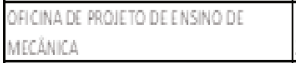 & 3 & & & 0 & 0 & 0 & 0 & 0 & 0,2 & 0 & 0 & 0,14285 & 0 & 0,2 & 0 & 0 & 0 & 0 \\
\hline $\begin{array}{l}\text { PLANELAMENTO E AVALIACRO DA } \\
\text { APRENDZLCLM }\end{array}$ & 3 & & & 0 & 0 & 0 & 0 & 0 & & 0 & 0 & 0 & 0 & 0 & 0 & 0 & 0 & 0 \\
\hline ELTRIOMAGNETISMO ALSICO & 4 & & & & & 0,160607 & 0 & 0,2 & 0,5 & 0,375 & 0 & 0,106667 & 0,394615 & 0 & 0,160467 & 0,06667 & 0,131313 & 0.2 \\
\hline ESTATESTICA & 4 & & & & 0 & 0 & 0 & 0 & 0 & 0 & 0 & 0 & 08 & 0 & 1 & 0 & 0 & 0,25 \\
\hline $\begin{array}{l}\text { INTRODUCTOTO A CIÉNCIA DA } \\
\text { COMPUTACTOO }\end{array}$ & 4 & & & & 0 & 0 & 0 & 0 & 0 & 0,125 & 0,111111 & 0 & 0,125 & 0 & 0 & 0,111111 & 0,571429 & 0,125 \\
\hline MÉTODOS MATEMATIICOS II & 4 & & & & & 0.393333 & 0 & 0 & 0 & 0 & 0,057143 & 0,666607 & 0 & 0,181919 & $a$ & 0 & 0 & 0,166667 \\
\hline $\begin{array}{l}\text { OFICINA DE PROSETO DE ENSINO OE FISICA } \\
\text { TÉRMICA }\end{array}$ & 4 & & & & & 0 & 0 & 0 & 0 & 0 & 0 & 0 & 0 & 0 & 0 & 0 & 0,142857 & 0 \\
\hline $\begin{array}{l}\text { POLLTICA EDUCACLONAL E FORMLC,FO DE } \\
\text { PROFESORES NO ERUSIL }\end{array}$ & 4 & & 0 & & 0 & 0 & 0 & 0 & & 0 & 0 & 0 & 0 & 0 & 0 & 0 & 0 & 0 \\
\hline 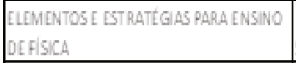 & 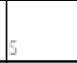 & & & & & & 0 & 0 & 0 & 0 & 0 & 0 & & 0 & 0 & 0 & 0 & 0 \\
\hline FBSAMODOENAII & 5 & & & & & & 0 & 0 & 0 & 0 & 0 & 0 & 0,166667 & 0 & 0,285714 & 0 & 0 & 0 \\
\hline FBSALONGLLATOALA & 5 & & & & & & 0 & 0 & 0 & 0 & 0,25 & 0 & 0 & 0,222222 & 0 & 0 & 0 & 0 \\
\hline LlendS & 5 & & & & & 0 & 0 & 0 & 0 & 0 & 0 & 0 & 0 & 0 & 0 & 0 & 0 & 0 \\
\hline MECANICA ANALITICA & 5 & & & & & & 0 & 0 & 0 & 0 & 0 & 0 & 1 & 0,3313ב3 & 0 & 0,666667 & 0,1 & 0,272727 \\
\hline 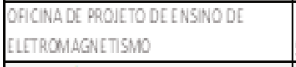 & 5 & & & & & & 0 & 0 & 0,2 & 0 & 1 & 0 & 0 & 0 & 0 & 0,4 & 0 & 0 \\
\hline $\begin{array}{l}\text { A EVOLUC,HO DO PENSAMENTO } \\
\text { CIENTFFCO }\end{array}$ & 6 & & & & & & & 0 & 0 & 0,166667 & 0 & 0 & 0 & 0 & 0 & 0 & 0 & 0 \\
\hline FISCLA MODCRNA III & 5 & & & & & & & 0 & 0 & 0 & 0 & 0 & 0,33933 & 0 & 0 & 0 & 0 & 0 \\
\hline $\begin{array}{l}\text { OFICINA DE PROIETO DEENSINO DE FISICA } \\
\text { ONDULAT ORLA E FISICA MODERNA }\end{array}$ & 5 & & & & & & & 0 & 0 & 0 & 0 & 0 & 0 & 0,16666 & 0 & 0 & 0 & 0 \\
\hline PSICOLOGIAAPLICADA A EDUCACFOO & 5 & & & & & & 0 & 0 & & 0,074074 & 0 & 0.1 & 0 & 0 & 0,2 & 0,331333 & 0 & 0 \\
\hline TOPICOS DE ELETROMAGNETISMO & 6 & & & & & & & 0 & 0 & \begin{tabular}{|l|}
0 \\
\end{tabular} & 0 & 0 & 0 & & 0 & 0,5 & 0 & 0 \\
\hline MECANICA ESTATISTLA & 7 & & & & & & & & 0 & 0 & 0 & 0 & 0 & & 0 & 0 & 0 & 0 \\
\hline WEODOLOGIA GA PESOUISA CIENT FICA & 7 & & & & & & & & 0 & 0 & 0 & 0 & 0 & 0 & 0 & 0 & 0 & 0 \\
\hline $\begin{array}{l}\text { PRAT CADE ENSWNO · ESTAGIO } \\
\text { IUPCRVISONADOI }\end{array}$ & 7 & & & & & & & & 0 & 0 & 0 & 0 & 0 & & 0 & 0 & 0 & 0 \\
\hline PROIEOFNALI I & 7 & & & & & & & & 0 & 0 & 0 & 0 & 0 & & 0 & 0 & 0,166667 & 0 \\
\hline QUAlWiCAGERAL & 7 & & & 0 & & & 0 & & 0,093333 & 0 & 0 & 0,1666067 & 0 & 0 & 0 & 0,125 & 0,331333 & $0,13: 323$ \\
\hline $\begin{array}{l}\text { PRATIICADE ENSINO - ESTALGID } \\
\text { SUPERVIONADO II }\end{array}$ & 8 & & & & & & & & & 0 & 0 & 0 & 0 & 0 & & 0 & 0 & 0 \\
\hline PROJETOFINAL II & 蒠 & & & & & & & & & 0 & 0 & 0,33333 & 0 & 0,5 & 0,66667 & 0,5 & 0,555556 & 0,1 \\
\hline $\begin{array}{l}\text { TOPICOS APLLADOOS DE FISICA } \\
\text { CONTEMPORANNEA }\end{array}$ & 8 & & & & & & & & & 0 & 0 & 0 & 0 & 0 & & 0 & 0 & 0 \\
\hline
\end{tabular}

Dessa forma, uma preocupação maior com a transição do ensino médio para o ensino superior era necessária logo nos primeiros períodos. Disciplinas avançadas de Matemática e Física deveriam ser precedidas de disciplinas introdutórias. Novos métodos de ensino deveriam facilitar os alunos nessa transição. Além disso, essas disciplinas introdutórias com novas metodologias poderiam também ser aproveitadas como motivação para permanência no curso, buscando resolver o problema da falta de interesse dos alunos nos períodos iniciais.

Outra razão importante para a evasão é a falta de adaptação ou dificuldade de instalação na cidade onde o curso é oferecido. Uma parcela dos alunos ingressantes é oriunda de outras cidades que não possuem oferta de cursos superiores públicos e gratuitos, tais como as 
da baixada e litoral fluminense, que chegam até a instituição através do Sistema de Seleção Unificada (SiSU).

Uma solução parcial para esse problema é a prática da assistência estudantil. Em nosso campus, bolsas de estudos são oferecidas para os alunos que preenchem requisitos associados à renda. Porém, elas não são suficientes para cobrir todos os alunos que realmente necessitam.

\section{II.2 Avaliação de reconhecimento do Curso pelo MEC - 2014}

A avaliação in loco de reconhecimento do curso pelo MEC ocorreu em agosto de 2014, após aproximadamente cinco meses de iniciado o processo através do preenchimento do formulário eletrônico e-MEC. Os itens de avaliação são os do Instrumento de Avaliação (IA) de Cursos de Graduação Presencial e a Distância, de maio de 2012 (BRASIL, 2012), que estava vigente no momento da visita dos avaliadores.

O IA de 2012 contém três dimensões: (1) Organização didático-pedagógica, com 17 indicadores aplicáveis ao nosso curso, entre os quais estão perfil do egresso, estrutura e conteúdos curriculares, estágio curricular supervisionado; (2) Corpo docente, contendo 12 indicadores aplicáveis ao curso, como por exemplo, atuação do Núcleo Docente Estruturante (NDE), atuação do coordenador, titulação e produção docente; (3) Infraestrutura, com 10 indicadores que se aplicam ao curso, entre eles, gabinetes de professores, salas de aula, laboratórios, biblioteca e acesso à informática. De acordo com o IA vigente à epoca, para os casos de reconhecimento de curso, a dimensão (1) tinha peso 40 e as demais peso 30.

Para cada indicador, no IA da época, havia um conceito a ser aplicado pelo avaliador que varia de 1, quando a Instituição de Ensino Superior não contempla ou não contém o item avaliado, até 5, quando a IES apresenta de forma excelente aquele indicador avaliado. Além dos indicadores, o IA apresentava na parte final do documento os requisitos legais e normativos, como a coerência do PPC com as DCN, as questões de acessibilidade, a existência da disciplina de Libras, dentre outros.

Após a avaliação in loco, os avaliadores emitiram um parecer no qual destacaram alguns indicadores avaliados e justificaram a atribuição dos conceitos considerados baixos. $\mathrm{O}$ Conceito Final do Curso foi 4, cujas médias parciais foram: Dimensão 1 - 3,5; Dimensão 2 4,5; Dimensão 3 - 4,2.

A menor média obtida foi justamente na dimensão relacionada à organização didático-pedagógica. Por esse motivo, ela foi analisada com maior profundidade para subsidiar a mudança curricular apontada como necessária pelos avaliadores.

Os indicadores com os menores conceitos associados com essa dimensão estavam relacionados com a estrutura e os conteúdos da matriz curricular, com o ES e com a ineficácia dos métodos de autoavaliação. Nesse sentido, cabe citar:

- A estrutura curricular apresentava os conteúdos bem distribuídos, como prevê o $\mathrm{Pa}$ recer CNE/CES 1304/2001 (BRASIL, 2001), mas foi criticada pelos avaliadores porque havia 
muitas disciplinas que eram relacionadas diretamente a um bacharelado. Segundo os avaliadores, elas poderiam ser convertidas em optativas. Da mesma forma, dever-se-ia realizar a inclusão de disciplinas obrigatórias e optativas diretamente relacionadas à formação de professores de física;

- A carga horária do curso somava 2.800 horas como determinava a Resolução $\mathrm{CNE} / \mathrm{CP}$ 02/2002. Porém, os avaliadores argumentaram que havia parte da carga horária (54 horas-aula) de PCC em disciplinas optativas, subtraindo, portanto, das 400 horas mínimas previstas pela resolução;

- O ES apresentava a carga horária total determinada pela mesma resolução. No entanto, a interpretação dos avaliadores era de um modelo de estágio tal que o licenciando deveria estar sempre na sala de aula da escola de educação básica, excluindo, assim, das horas de estágio os momentos de reflexão-sobre-ação realizados a posteriori. Em nosso modelo, as horas de planejamento e reflexão contabilizavam como parte da estrutura do ES.

Além dessas avaliações relativas à estrutura curricular na dimensão 1, havia ainda itens dos requisitos legais que não eram atendidos pelo curso. Faltavam, de forma sistêmica no Currículo Antigo, conteúdos associados à educação ambiental e à inclusão.

\section{II.3 Resolução 02/2015 CNE/CP}

A aprovação do Plano Nacional de Educação (PNE) em junho de 2014 inaugurou uma nova fase das políticas públicas educacionais no Brasil (DOURADO, 2015). Organizado num conjunto de 20 metas, o PNE discute sobre todas as instâncias da educação. Sobre a formação de professores, a meta 15 e suas estratégias tratam da formação inicial e continuada de professores. Em decorrência da necessidade de cumprimento do PNE, foi articulada pelo Conselho Nacional de Educação (CNE), numa junção Bicameral entre as Câmaras de Educação Básica e de Educação Superior, a elaboração de Novas DCN para a formação inicial e continuada de professores.

O texto resultante dessas discussões foi publicado em junho de 2015 como o Parecer CNE/CP 02/2015 do Conselho Pleno do CNE. Desse texto, originaram as DCN para a formação inicial e continuada de professores, publicadas em $1^{\circ}$ de julho de 2015 sob a forma da Resolução CNE/CP 02/2015 (BRASIL, 2015).

As novas DCN definem os princípios da formação inicial e continuada de profissionais do magistério da educação básica e sinalizam para maior organicidade nos projetos formativos, necessidade de maior articulação entre as instituições de educação superior e de educação básica, definindo que a formação inicial e continuada deve contemplar:

I. Sólida formação teórica e interdisciplinar dos profissionais;

II. A inserção dos estudantes de licenciatura nas instituições de educação básica da rede pública de ensino, espaço privilegiado da práxis docente; 
III. O contexto educacional da região onde será desenvolvido;

IV. Atividades de socialização e avaliação dos impactos;

$V$. Aspectos relacionados à ampliação e ao aperfeiçoamento do uso da língua portuguesa e à capacidade comunicativa, oral e escrita, como elementos fundamentais da formação dos professores e à aprendizagem de Libras;

VI. Questões socioambientais, éticas, estéticas e relativas a diversidade étnicoracial, de gênero, sexual, religiosa, de faixa geracional e sociocultural como princípios de equidade” (DOURADO, 2015 p. 28).

A resolução traz alterações importantes nas cargas horárias às quais os cursos devem obedecer. A carga horária total deve ser de, no mínimo, 3.200 horas de efetivo trabalho acadêmico em cursos com duração de, no mínimo, 8 semestres, distribuídas da seguinte forma: 400 horas de PCC, 400 horas de ES, 2.200 horas de horas dedicadas a atividades formativas, 200 horas de atividades teórico-práticas. Cabe ressaltar que a resolução estabelece o prazo de 2 anos para os cursos de licenciatura se adequarem às novas DCN.

Tendo em vista o exposto na Seção II.2 acerca da avaliação do nosso curso pelo MEC, percebe-se uma consonância entre o que foi estabelecido pelas DCN e os pontos apontados pelos avaliadores como desejáveis. Alia-se a isso o desejo latente de grande parte do corpo docente de transformar o curso em um espaço de formação de professores de excelência a partir de um trabalho orgânico entre teoria e prática. Esse era o ponto mais nevrálgico para um possível projeto de reformulação curricular tendo em vista as especificidades dos sujeitos que compõem o corpo docente (bacharéis e licenciados). Não é nosso intuito com esta afirmação fazer juízo de valores a uma ou outra especificidade, mas é fundamental apontar que as diferentes formas de olhar a Física fazem parte do nosso contexto e devem ser consideradas, pois são fundamentais para a construção da identidade do curso que pretendemos.

Enfatizando a institucionalização da formação inicial dos profissionais do magistério para a educação básica, as novas DCN definem que essa formação proposta requer projeto com identidade própria de curso de licenciatura sem prescindir de articulação, no que couber, com os cursos de bacharelado ou tecnológico, a outra(s) licenciatura(s) ou a cursos de formação pedagógica de docentes.

Nesse sentido, as DCN colaboraram para a resolução de um ponto polêmico entre os docentes do curso: a necessidade de se ampliarem as discussões pedagógicas. $\mathrm{O}$ aumento da carga horária total de 2.800 para 3.200 horas torna possível a inserção de mais disciplinas pedagógicas, bem como uma maior articulação com as disciplinas específicas (Física e Matemática) e, sobretudo, uma integração dessas disciplinas com o ES numa tentativa de consolidar a relação teoria e prática.

A necessidade de ampliar as discussões sobre espaços de formação pedagógica decorrem da inconsistência das novas DCN com o Currículo Antigo, que privilegiava mais os conteúdos específicos sem, necessariamente, articular estes conteúdos ao ensino de Física. Outro ponto de inconsistência era a questão do ES que, apesar de cumprir com as exigências 
legais e tentar articular a formação inicial dos professores, ou seja, o espaço universitário à escola básica, apresentava pontos frágeis que deveriam ser reforçados em uma reestruturação curricular.

Além disso, são marcantes duas características que diferenciam a Resolução CNE/CP 02/2015 da resolução anterior no que se refere à organização curricular. Primeiramente, estabelece três núcleos I, II e III, respectivamente, núcleo de formação geral, de aprofundamento e diversificação das áreas de atuação profissional e de estudos integradores. A outra característica são os eixos articuladores desses núcleos como critério de "organização matriz curricular, bem como de alocação de tempos e espaços" (BRASIL, 2015; p. 11).

\section{O desenvolvimento do novo currículo}

\section{III.1 O trabalho da Comissão de Reformulação do Currículo}

Em função do contexto apresentado anteriormente, que apontava problemas com evasão, interesse dos alunos nas disciplinas ministradas e suas dificuldades de aprendizagem, bem como a necessidade de atender às novas DCN's para a formação inicial e continuada de professores, foi designada, em 26 de maio de 2014, através da Portaria 621/2014, a Comissão de Reformulação do Currículo do Curso de Licenciatura em Física do campus Petrópolis do CEFET/RJ. Participaram desta comissão professores de todas as grandes áreas presentes no curso: Física, Ensino de Física, Matemática, Química, Pedagogia e Línguas/LIBRAS. Além disso, foi feito um convite aberto aos discentes ativos no curso e aos já formados para participarem da comissão. A configuração final da comissão, que foi recomposta duas vezes ao longo do processo, continha 2 professores pesquisadores em Física, 3 professores licenciados em Física e pesquisadores em Ensino, 2 professores de Matemática atuantes na pesquisa em Matemática, 1 professor de Química atuante na pesquisa em Química, 1 professora pedagoga pesquisadora em em Educação, 1 discente formado e 2 discentes ativos no curso, entre os quais, alguns são autores deste trabalho.

O relatório produzido pelos avaliadores do MEC foi um documento norteador importante para os estudos e as ações da comissão. No âmbito legal, o Parecer 1304/2001 do Conselho do Ensino Superior do CNE que aprova as "Diretrizes Curriculares para os Cursos de Física" (BRASIL, 2001) e as Resoluções CNE/CP 01 e 02/2002 do CP do CNE que "institui DCN para a Formação de Professores da Educação Básica, em nível superior, curso de licenciatura, de graduação plena" (BRASIL, 2002a) e "institui a duração e a carga horária dos cursos de licenciatura, de graduação plena, de formação de professores da Educação Básica em nível superior" (BRASIL, 2002b) foram os principais documentos balizadores da reforma curricular. As resoluções apontam que os currículos dos cursos superiores devem se pautar em uma lista de habilidades e competências ali definidas.

A primeira diretiva do trabalho da Comissão de Reformulação foi começar todo o processo pelo perfil do egresso. Esse caminho se mostrou tortuoso, tanto pela falta de consen- 
so entre os integrantes da comissão sobre o perfil do egresso (sempre marcada pela tensão bacharelado x licenciatura), quanto pela dificuldade em articular esse perfil com as disciplinas, seus conteúdos e metodologias e avaliação. Essa tensão provocou em alguns membros da comissão a necessidade de se partir das concepções já existentes sobre o perfil de egresso e, então, começar de imediato a confecção da matriz de disciplinas e de suas ementas.

Quando diferentes visões acerca da formação começaram a emergir nos debates sobre quais disciplinas deveriam ou não estar presentes na matriz curricular, o grupo percebeu a dificuldade de fazer escolhas sem um critério balizador. Foi nesse contexto que surgiu a ideia da matriz de habilidades e competências do curso, construída a partir das definições contidas nos documentos oficiais (Anexo 3). A finalidade da matriz é servir como um norteador das escolhas epistemológicas e metodológicas na criação das disciplinas do novo currículo e na construção de suas ementas, visto que o conjunto de habilidades e competências que nela figuravam, definiam o perfil dos egressos do curso de licenciatura em física do CEFET/RJ, campus Petrópolis.

Como forma de sensibilizar os membros da comissão acerca da forma como vínhamos trabalhando a formação de nossos alunos no currículo antigo e diagnosticar o perfil dessa formação decidimos realizar uma análise de quais as competências e habilidades constantes em nossa matriz estavam sendo contempladas pelas disciplinas do currículo antigo. A tabela 3 apresenta todas as disciplinas do curso antigo, organizadas em ordem crescente de períodos, e todas as habilidades e competências consideradas no perfil do egresso. Cada habilidade contemplada é marcada com um X e uma cor.

Da tabela 3, é possível identificar alguns problemas da antiga versão curricular de nosso curso, sendo os principais deles:

1. As disciplinas de conteúdos específicos (C3) não se articulam com as disciplinas de conteúdos pedagógicos (C5), reproduzindo, portanto, as mesmas características do modelo $3+1$.

2. A competência C3 (Domínio dos princípios gerais e fundamentos da Física, em suas áreas clássica e moderna) é amplamente contemplada, enquanto que a C1 (Comprometimento com os valores inspiradores da sociedade democrática), C2 (Compreensão do papel social da escola) e C7 (Gerenciamento do próprio desenvolvimento profissional) quase não são. Essa análise mostra o forte caráter bacharelesco do curso, uma vez que competências importantes para a formação de professores apareciam eclipsadas frente a outras voltadas para outro perfil de formação.

Embora reconhecendo a pertinência de muitas das críticas inerentes a organizações curriculares norteadas por competências e habilidades (LOPES, 2001), entendemos naquele momento sua funcionalidade no desafio de fugir das listas de conteúdos e disciplinas naturalizadas. Esse foi o instrumento negociado pela comissão a fim de relacionar de fato conteúdos e disciplinas e o perfil formativo desejado. 
Tabela 3 - Habilidades e competências contempladas em cada disciplina do Currículo Antigo do em acordo com os critérios estipulados pela Comissão de Reformulação.

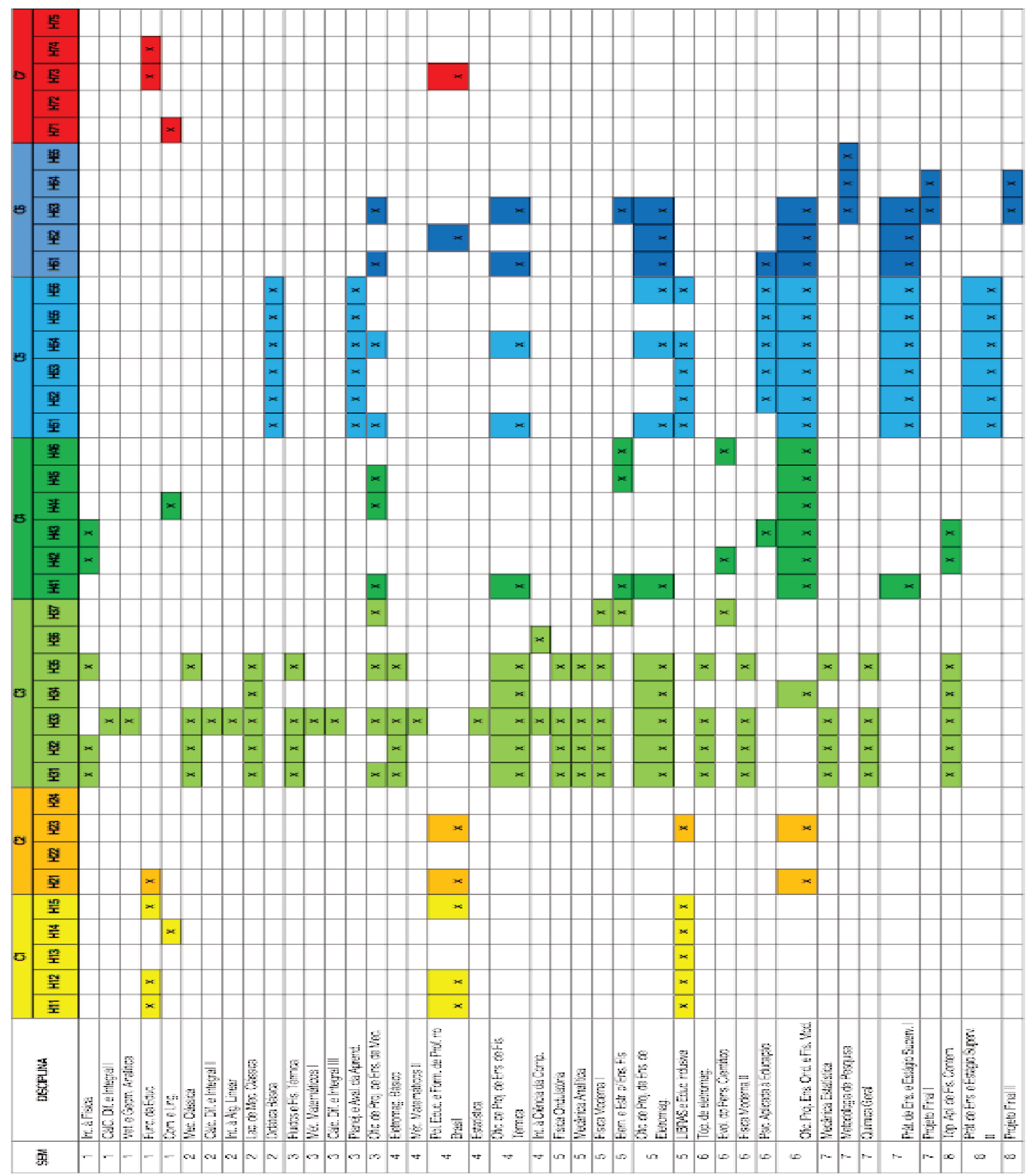

Após esse trabalho analítico, a comissão passou a discutir e delinear novos espaços curriculares na forma de disciplinas que pudessem melhor cumprir o papel formador proposto pelos documentos legais. Além disso, levou-se em consideração a demanda social e as expectativas dos próprios discentes em relação aos conteúdos curriculares e os caminhos formativos esperados. Nessa perspectiva, foram definidas as ementas, as cargas horárias, os objetivos, a 
bibliografia e as competências e habilidades que deveriam ser contempladas por cada disciplina. Para além das ementas, foram confeccionadas máscaras para cada disciplina, que continham todas essas informações, a fim de garantir a articulação entre o planejamento da disciplina e o perfil do egresso.

A versão antiga do currículo do nosso curso apresentava os principais índices de retenção e evasão nas disciplinas de Física e Matemática dos primeiros períodos. Uma solução paleativa foram algumas disciplinas optativas de nivelamento nos primeiros períodos, tais como Matemática Básica, Nivelamento em Mecânica Clássica e Introdução às Ciências Experimentais. A partir dessa experiência, a Comissão optou por incorporar essas disciplinas como obrigatórias em sua nova versão curricular. Além disso, a disciplina Mecânica Clássica foi dividida em duas com o objetivo de trabalhar de forma melhor distribuído um conteúdo extenso e de fundamental importância para a Física, possibilitando o n desenvolvimento de diferentes metodologias de ensino.

A prática experimental da Física, que antes acontecia em disciplinas específicas, seria no novo currículo parte da ementa e da carga horária das disciplinas de Física Básica. A finalidade é articular teoria e prática permitindo a apresentação fenomenológica aliada à modelagem e resolução teórica dos problemas físicos.

No que tange aos períodos mais avançados, a comissão optou por retirar diversas disciplinas obrigatórias da grade antiga e inserir carga horária equivalente em disciplinas optativas (6 disciplinas contabilizando 285 horas no total). As disciplinas optativas, por sua vez, permitiriam aos alunos delinear sua trajetória formativa, definindo a ênfase de sua formação profissional.

Os trabalhos da Comissão duraram 1 ano e 4 meses e foram finalizados com a produção de um relatório, o qual foi entregue e apresentado ao colegiado deliberativo do curso para avaliação e definição da continuidade da reformulação. É importante destacar que, ao final dos trabalhos da Comissão, recebemos a notícia da publicação da Resolução $\mathrm{CNE} / \mathrm{CP}$ 02/2015. Em não havendo tempo hábil de considerar na íntegra os diversos aspectos que esta nova resolução determinava, a Comissão apontou em seu relatório alguns caminhos que poderiam ser seguidos e indicou que novos e continuados estudos precisavam ser feitos para adequação completa do currículo a esse novo documento norteador. A continuidade desse trabalho foi feita pelo Núcleo Docente Estruturante (NDE).

Uma das alterações mais impactantes da Resolução foi o aumento de 400 horas na carga horária total do curso, passando de 2.800 horas para 3.200 horas mínimas. O NDE teve que tomar a difícil decisão de estender o curso para 9 períodos semestrais de forma a manter o curso exclusivamente noturno e ainda implementar uma redução na carga horária diária máxima de 4 horas e 10 minutos ininterruptas para 4 horas com um intervalo de 15 minutos, ou seja, cada aula passaria a ter 45 minutos ao invés de 50. Essa redução da carga horária total já acontecia na prática, uma vez que a maioria dos alunos chegava no curso 15 minutos atrasada e saia 15 minutos adiantada por conta de diversos fatores, tais como, horário de trabalho, ofer- 
ta de transporte coletivo, dentre outros. O NDE considerou que essa nova realidade acolheria melhor as necessidades dos alunos frequentadores do curso.

A fim de responder as especificidades das novas DCN, o NDE estruturou a matriz curricular do novo curso a partir de quatro Eixos Articuladores (EA), como apresentados no Quadro 3 (CEFET/RJ, 2016).

Quadro 3 - Definição dos Eixos Articuladores atribuídos às disciplinas do novo curso.

\begin{tabular}{|c|c|c|}
\hline Eixo & Descrição & Núcleo \\
\hline Formação Específica & $\begin{array}{l}\text { Conjunto de disciplinas e outras atividades formativas de ca- } \\
\text { ráter geral, relacionados aos conhecimentos da área específi- } \\
\text { ca. }\end{array}$ & \multirow{2}{*}{ I } \\
\hline Formação Pedagógica & $\begin{array}{l}\text { Conjunto de disciplinas e outras atividades formativas de ca- } \\
\text { ráter geral, relacionados aos conhecimentos do campo educa- } \\
\text { cional. }\end{array}$ & \\
\hline Iniciação à Docência & $\begin{array}{l}\text { Conjunto de disciplinas e outras atividades formativas relaci- } \\
\text { onadas aos fundamentos teórico-metodológicos do ensino e } \\
\text { aprendizado da Física, necessários à formação inicial docente. }\end{array}$ & II \\
\hline Extensão e Pesquisa & $\begin{array}{l}\text { Conjunto de disciplinas e outras atividades formativas direta- } \\
\text { mente relacionadas com a Extensão e a Pesquisa, nos seus } \\
\text { diversos contextos. }\end{array}$ & III \\
\hline
\end{tabular}

Nos EA Formação Específica e Formação Pedagógica estão articuladas as disciplinas e outras atividades formativas relacionadas ao Núcleo I "de formação geral, das áreas específicas e interdisciplinares, e do campo educacional, seus fundamentos e metodologias, e das diversas realidades educacionais" (BRASIL, 2015, p. 9).

Neste eixo estão articuladas as disciplinas dos conteúdos de Física Geral, Matemática, Física Clássica, Física Moderna e Contemporânea e Química, como estabelece o Parecer CNE/CES 1304/2001. Enquanto no EA Formação Pedagógica articulam-se as disciplinas pedagógicas, buscando garantir "ao longo do processo, efetiva e concomitante relação entre teoria e prática, ambas fornecendo elementos básicos para o desenvolvimento de conhecimentos e habilidades necessários à docência" (BRASIL, 2015, p. 11). Da mesma forma, o EA Formação Pedagógica garante que o tempo dedicado às disciplinas e outras atividades formativas de dimensões pedagógicas não seja inferior à quinta parte da carga horária total da matriz curricular.

O EA Iniciação à Docência articula as disciplinas de ensino de física, relacionadas ao aprender a ensinar, fundamentos teóricos e metodológicos para o ensino e aprendizado da Física, isto é, relacionadas ao Núcleo II. Este é definido como o "núcleo de aprofundamento e 
diversificação de estudos das áreas de atuação, incluindo os conteúdos específicos e pedagógicos" (ibidem, p. 10).

Nele estão articuladas as disciplinas e outras atividades formativas que articulam as teorias educacionais e os conhecimentos advindos da pesquisa em Ensino de Física. As disciplinas de Oficinas de Projeto de Ensino, Práticas Docentes e as Optativas de Escolha Restrita estão articuladas nesse EA. Dessa forma, busca-se proporcionar aos licenciandos atividades de planejamento e de desenvolvimento de diferentes experiências didáticas em Física, como elaboração de materiais de diferentes naturezas para a Educação Básica, incluindo as modalidades da EJA e Educação Especial.

Já o EA Extensão e Pesquisa articula as disciplinas e outras atividades formativas do Núcleo III "de estudos integradores para o enriquecimento curricular", no qual envolve participação em seminários, projetos de iniciação à docência e iniciação científica, entre outras atividades.

O EA Extensão e Pesquisa articula a disciplina Práticas Extensionistas a outras atividades formativas, especificamente, as atividades teórico-práticas de aprofundamento das áreas específicas de interesse dos licenciandos. A principal forma de articulação é por meio de desenvolvimento e participação em projetos de extensão, pesquisa ou ensino oferecidos pelos docentes do Curso.

Assim, os EA que organizam a matriz curricular fundamentam-se na ideia de que

aprender a ser professor (...) não é, portanto, tarefa que se conclua após estudos de um aparato de conteúdo e técnica de transmissão deles. É uma aprendizagem que deve se dar por meio de situações práticas que sejam efetivamente problemáticas, o que exige o desenvolvimento de uma prática reflexiva competente (...). Assim, o modelo da racionalidade técnica não mais dá conta da formação dos professores (MIZUKAMI, 2002, p. 12).

\section{O Currículo Novo}

Nas subseções que seguem são apresentadas as principais mudanças que se constituíram como respostas aos problemas verificados no currículo antigo. A versão mais atualizada do novo currículo pode ser encontrada na página oficial de internet da instituição (CEFET/RJ, 2016). No Anexo 1, apresentamos o fluxograma contendo as disciplinas distribuídas em períodos letivos, seus pré-requisitos e a carga horária semestral (no rodapé), dividida entre conteúdos formativos, PCC e ES.

\section{IV.1 Disciplinas introdutórias nos primeiros períodos}

Longe de considerar que o problema da transição ensino médio - ensino superior é de um simples nivelamento, o NDE resolveu tratar com muita atenção os primeiros períodos do curso. Dessa forma, muitas disciplinas introdutórias foram inseridas, em especial no pri- 
meiro período, tais como Introdução à Astronomia, Introdução às Ciências Experimentais, Introdução à Física e Computação Algébrica. Além de fornecer conhecimentos básicos para a continuidade no curso, essas disciplinas visavam também "seduzir" os alunos com o mundo da Física e da Matemática, trazendo metodologias de ensino diferenciadas. As outras disciplinas que compõem o primeiro período são Matrizes e Vetores e Funções.

O principal objetivo de inserir a disciplina introdutória de Astronomia no primeiro período foi a preparação para a Mecânica, cuja primeira parte ocorre logo no segundo período e sempre foi um grande motivo de retenção em nosso curso, como descrito na seção 2.1. Além disso, ela apresenta um caráter motivacional, pois aborda diversas questões da Física do cotidiano. A disciplina de Introdução à Física manteve o caráter da versão curricular anterior, objetivando apresentar todas as áreas da Física de uma forma panorâmica, bem como enfatizar suas conexões. A disciplina de Introdução às Ciências Experimentais tem como objetivo não apenas instrumentalizar os alunos com os conhecimentos acerca do processo de medição experimental que será útil para as disciplinas seguintes, mas também de discutir o papel da experimentação na ciência de uma forma geral.

A principal mudança, em termos metodológicos, ocorreu nas disciplinas que envolvem mais os saberes matemáticos. Todas foram integradas ao uso de ferramentas computacionais com o auxílio do laboratório de informática do campus. As aulas dessas disciplinas foram divididas em teoria/prática, com distribuição percentual de carga horária de 60/40, respectivamente. Originalmente, previu-se a utilização dos seguintes programas computacionais para contemplação da proposta: Maple (adquirido pelo campus), Geogebra, Matlab (ou versões gratuitas dessa plataforma), Mathematica, dentre outros. O uso desses programas deveria se dar de forma bastante abrangente, com aplicações indo desde o desenvolvimento do conteúdo à resolução de problemas e avaliações. Além do caráter motivacional que essas disciplinas possuem, contribuindo para um maior envolvimento e entusiasmo do aluno no seu processo educativo através do uso de novas tecnologias no ensino, elas buscam auxiliar o aluno a superar suas deficiências na formação elementar e, consequentemente, auxiliar nas primeiras disciplinas do curso nas áreas de Matemática e Física. De modo especial, a disciplina Computação Algébrica apresenta diferentes recursos computacionais que poderão auxiliar os alunos em suas futuras práticas letivas, desenvolvendo neles a capacidade de investigar e utilizar tais recursos de forma autônoma.

Assim, levando em consideração os EA e a distribuição das disciplinas no currículo novo, o NDE elaborou uma cadeia de pré-requisitos que visa não só garantir o estudo prévio de conteúdos considerados essenciais e correlatos entre as disciplinas, mas também garantir uma melhor articulação das disciplinas a fim de possibilitar ao licenciando uma trajetória formativa com menor índice de reprovações. 


\section{IV.2 Disciplinas optativas como caminhos profissionais}

A ideia proposta pela Comissão de Reformulação de permitir ao discente definir sua trajetória formativa a partir de disciplinas optativas foi mantida pelo NDE na nova versão curricular. A carga horária, no entanto, foi aumentada e passa a compor 310,5 horas dos 3 últimos períodos, ou $40 \%$, se não contabilizarmos as horas de estágio. Além de oferecer essa autonomia ao aluno, essa prática soluciona um outro problema grave da versão antiga de nosso currículo: retirar da grade obrigatória as disciplinas de Física típicas de um curso de bacharelado.

A obrigação de cumprir essas disciplinas disciplinas avançadas na área de Física, como por exemplo, Mecânica Estatística, descaracterizava, em certo sentido, um curso de licenciatura. Além disso, a presença dessas disciplinas na grade curricular obrigatória foi alvo de críticas dos avaliadores do MEC quando do reconhecimento do curso, um dos principais fatores para a redução de nossa nota final, como apresentado na seção II.2.

Para permitir uma ampla escolha de caminhos formativos, as disciplinas optativas se dividem em dois grupos, as de escolha restrita e de escolha livre. Dentro do quadro de disciplinas optativas de escolha restrita, estão contidas disciplinas do núcleo da Física e do Ensino de Física, sendo que os alunos podem escolher quantas quiserem de cada núcleo e, no mínimo uma pertencente a cada grupo, até completar a carga horária total de optativas. Dessa forma, nenhum aluno sai formado no curso sem ter visto as duas grandes áreas formativas e, ao mesmo tempo, garante-se os conhecimentos consideradas mínimos nas áreas de conhecimento que envolvem diretamente suas opções de continuidade nos estudos.

O Quadro 4 apresenta a lista das disciplinas optativas. Cabe ressaltar que as disciplinas optativas de escolha livre são oferecidas de acordo com a demanda ou pela oferta espontânea dos professores do colegiado. As disciplinas apresentadas nessa categoria são apenas exemplos de possibilidades.

Quadro 4 - Lista de disciplinas optativas.

\begin{tabular}{|c|c|c|}
\hline \multicolumn{2}{|c|}{ Disciplinas Optativas de Escolha Restrita } \\
\hline Ensino de Física & \multicolumn{2}{c|}{ Física } \\
\hline Teoria de Currículo & \multicolumn{2}{c|}{ Tópicos Avançados de Mecânica Clássica } \\
\hline Introdução à Pesquisa em Ensino de Física & \multicolumn{2}{|c|}{ Mecânica Estatística } \\
\hline $\begin{array}{c}\text { Formação de Professores de Ciências e Mate- } \\
\text { mática }\end{array}$ & \multicolumn{2}{|c|}{ Tópicos Avançados de Eletromagnetismo } \\
\hline \multicolumn{2}{|c|}{ Ciência e Cultura } & \multicolumn{2}{c|}{ Mecânica Quântica } \\
\hline \multicolumn{2}{|c|}{ Disciplinas Optativas de Escolha Livre } \\
\hline Másica & Ens. de Ciências & Outros \\
\hline
\end{tabular}




\begin{tabular}{|c|c|c|c|}
\hline Análise Real & $\begin{array}{c}\text { Introdução à Física de } \\
\text { Partículas }\end{array}$ & $\begin{array}{c}\text { Est. Socioculturais em } \\
\text { Ens. de Ciências e } \\
\text { Matemática }\end{array}$ & $\begin{array}{c}\text { Introdução à Espec- } \\
\text { troscopia }\end{array}$ \\
\hline Cálculo Numérico & $\begin{array}{c}\text { Introdução à Física da } \\
\text { Matéria Condensada }\end{array}$ & $\begin{array}{c}\text { Estudos em História } \\
\text { da Ciência }\end{array}$ & Inglês Instrumental \\
\hline $\begin{array}{c}\text { Introdução à Lógica } \\
\text { Física Nuclear }\end{array}$ & $\begin{array}{c}\text { Ciência, Tecnologia e } \\
\text { Sociedade }\end{array}$ & Química geral II \\
\hline $\begin{array}{c}\text { Introdução à Geome- } \\
\text { tria Diferencial }\end{array}$ & $\begin{array}{c}\text { Introdução à Física } \\
\text { Atômica e Molecular }\end{array}$ & Biofísica & Química Geral Exp. \\
\hline $\begin{array}{c}\text { Matemática Financei- } \\
\text { ra }\end{array}$ & Astronomia Avançada & Epistemologia II & \\
\hline
\end{tabular}

Nesta divisão em núcleos, tentamos contemplar os conteúdos avançados das grandes áreas. Dessa forma, um aluno com o perfil de pesquisa em qualquer uma das áreas pode cursar as 4 disciplinas optativas de escolha restrita deste núcleo e ainda as disciplinas optativas de escolha livre relacionadas à sua área de interesse. Já outro aluno que não se interesse por dar continuidade aos seus estudos através da pesquisa formal pode cursar disciplinas optativas que julgue que irão lhe proporcionar ferramentas mais adequadas aos seus futuros interesses profissionais.

\section{IV.3 As disciplinas do Eixo Articulador Formação Específicas}

As disciplinas de Física contabilizam 729 das 2.200 horas de atividades formativas ou de conteúdo do curso. Essa parte do currículo se trata de um núcleo duro que tem uma forma já muito naturalizada (BARCELLOS, 2013). As diversas discussões e estudos permitiram à reelaboração curricular aqui apresentada realizar alterações julgadas possíveis num quadro de professores de Física experientes, já bastante arraigados às suas práticas e dos quais muitos sem formação pedagógica.

Uma das inovações trazidas na nova versão curricular consiste em integrar a parte experimental e a parte teórica da Física em boa parte das disciplinas. Do total de horas dedicadas, $28 \%$ são de atividades experimentais efetivas, que acontecem conjuntamente com a teoria durante as disciplinas de Física básica. A opção por adotar essa metodologia é baseada em diversos estudos que apontam que a prática laboratorial desconectada da fundamentação teórica relacionada aos fenômenos estudados pode ser um grande problema para a aprendizagem da Física e sua significação, tanto nas características do conhecimento em si, quando de elementos e estratégias para seu ensino, em que se faz necessária sua contextualização (LEITE; ESTEVES, 2005; PINHEIRO, 2009; ANDRADE, 2011; FEIX, 2012). Nesse sentido, quase todas as disciplinas tradicionais da Física têm em sua carga horária uma parte explici- 
tamente designada às aulas experimentais. Além disso, a ementa enfatiza a ideia de que a parte teórica e a parte experimental sejam articuladas e integradas na medida do possível.

Assim, inserido no EA Formação Específica, encontram-se as disciplinas mais tradicionais de Física (vide fluxograma Anexo 1). No segundo período, encontra-se a disciplina Mecânica Básica I, cujos conteúdos se complementam no terceiro período com a disciplina Mecânica Básica II. Ao particionar os conteúdos da ementa em dois blocos, onde se vê inicialmente a dinâmica da partícula e as leis de conservação e, em seguida, a dinâmica do sistema de partículas e de sistemas contínuos, pretendemos dar à disciplina um ritmo mais tranquilo para que os alunos tenham mais possibilidades de se adequar as rotinas próprias das disciplinas da Física. Além disso, conforme discutido anteriormente, esperamos que a apresentação da fenomenologia aliada ao conteúdo teórico auxilie na aprendizagem.

A Física é complementada com a disciplina Física Térmica no terceiro período. Nessa disciplina, apresenta-se o conteúdo básico da Termodinâmica, aliando as grandezas e relações termodinâmicas macroscópicas empíricas com as teorias microscópicas estatísticas associadas. Nesse sentido, buscamos uma maior integração entre os conhecimentos obtidos das disciplinas de mecânica com o ensino-aprendizagem da termodinâmica.

O quarto período é dedicado ao Eletromagnetismo, que é contemplado em duas disciplinas. A primeira, Eletromagnetismo Básico, de caráter exclusivamente teórico, é, praticamente uma abordagem dessa área do conhecimento pelas equações de Maxwell. O modelo microscópico da matéria para a compreensão da carga elétrica, dos processos de eletrização, magnetização e dos fenômenos de transporte também estão presentes. A segunda disciplina, Circuitos Elétricos e Eletrônicos, tem como função a aprendizagem de outra parte do Eletromagnetismo, de forma eminentemente prática. Em princípio, as duas disciplinas não dependem uma da outra, uma vez que seus conteúdos são autossuficientes. Por outro lado, alguns conteúdos se repetem em abordagens diferentes. Enquanto o aluno participa de uma discussão mais teórica acerca dos conceitos fundamentais do eletromagnetismo na primeira disciplina, percebe também suas aplicações práticas na última. Alguns temas tradicionalmente abordados de forma também puramente teórica como os circuitos, serão vistos apenas aliados à sua forma prática, na qual tem mais possibilidades de significação.

Os conceitos relacionados à Física Clássica são finalizados com a disciplina Física Ondulatória e Óptica, no quinto período, que também contempla carga horária em laboratório. Sua ementa é bem padrão com toda a parte relacionada às ondas mecânicas e eletromagnéticas e aos fenômenos ondulatórios tratados pela óptica geométrica e pela óptica física. Ao final da disciplina, debatem-se princípios um pouco mais avançados, tais como o espectro eletromagnético, o efeito fotoelétrico e o funcionamento do LASER.

A partir do quinto período, a Física Moderna começa a fazer parte da grade curricular. Porém, diferente do que comumente é realizado, os aspectos históricos e filosóficos da ciência moderna são debatidos com maior cuidado, de forma a caracterizar com maior rigor os acontecimentos que levaram a grandes mudanças no paradigma científico e, especialmente, o 
da Física no fim do século XIX e início do século XX. Em uma disciplina específica chamada História e Filosofia da Física Moderna serão utilizadas fontes históricas e textos de Filosofia da Ciência em lugar da abordagem da reconstrução racional tradicionalmente presentes nos livros didáticos de Física. A História e a Filosofia se fazem presentes também na disciplina de Epistemologia do sétimo período, em que se visa discutir a natureza do conhecimento científico.

As disciplinas que integram o arcabouço da Física Moderna, além da disciplina História e Filosofia da Ciência Moderna são: Relatividade, Física Quântica, Introdução à Física Nuclear e Laboratório de Física Moderna. De todas essas, apenas a última tem carga horária de laboratório, onde, nesse caso, todo o conteúdo das anteriores é visto de forma prática. Como discutido anteriormente, essa não é a condição ótima para o processo de ensinoaprendizagem da Física Moderna, entretanto, considerando-se a baixa quantidade de experimentos disponíveis comercialmente e em nossos laboratórios, tivemos que adotar essa abordagem.

Por fim, visando possibilitar aos nossos alunos uma visão mais ampla e atualizada da Física, inserimos no oitavo período do curso a disciplina Discussões dos Conceitos de Física. Essa disciplina tem em seu escopo a promoção de discussões avançadas da física numa abordagem mais contemporânea, mas também visa resumir e correlacionar todo o conteúdo visto ao longo de todo o curso. De um ponto de vista global, podemos dizer que enquanto a disciplina Introdução à Física abre o curso apresentando um panorama da física, essa disciplina encerra os conteúdos de física do curso da mesma forma. Assim, o aluno tem a oportunidade de participar de discussões semelhantes tendo um arsenal de conhecimentos mais completo, o que lhe permite uma integralização maior de seus conhecimentos acerca da física.

\section{IV.4 As disciplinas do Eixo Articulador Formação Pedagógica}

Um dos maiores desafios encontrados pela Comissão de Reestruturação e, posteriormente pelo NDE, foi encontrar estratégias para a consolidação das disciplinas pedagógicas e para sua articulação com as disciplinas específicas ao longo do curso. Nossa empreitada era fazer com que os licenciandos percebessem a importância das discussões pedagógicas e, assim, colocá-las em igualdade com as disciplinas específicas.

Vale ressaltar que esse desafio não é problema exclusivo em nosso curso. Conforme Maldaner (2003):

o modelo adotado pelas Licenciaturas, fragmentando a formação, compromete a autoformação didático pedagógica de seus alunos, pois dicotomiza um processo de educação que deve ser global. Ao deixar apenas para um grupo de professores, geralmente de outro centro, no caso da educação, a formação didáticopedagógica, reduz o processo formativo e, consequentemente, a preparação docente de futuros professores (MALDANER, 2003, p. 89). 
Um dos avanços da nova versão curricular diz respeito à inserção de disciplinas pedagógicas com caráter reflexivo, tentando superar a ideia de que as disciplinas pedagógicas são apenas campos instrumentais e espaços de receitas prontas. A criação da disciplina Educação e Sociedade, no segundo período do curso, abre espaço para reflexões sociológicas e para uma forma mais ampla e contextualizada de pensar a educação. Além disso, permite relacionar a educação, a sociedade e o desenvolvimento da ciência como formas de compreender o mundo. Simultaneamente às discussões sociológicas, são realizadas também as discussões filosóficas e históricas da educação, em especial da educação brasileira na disciplina de Fundamentos Histórico-Filosóficos da Educação.

Realizadas as discussões sócio-histórico-filosóficas, abre-se espaço para as reflexões teórico-práticas dadas pelas disciplinas de Políticas Públicas e Formação de Professores, Didática e Psicologia Aplicada à Educação. Essas disciplinas buscam articulação imediata com outras disciplinas pedagógicas e específicas, sendo consolidadas nas disciplinas de OPE e de ES. Ao final do curso, a disciplina Sujeito, Sociedade e Cultura busca levar a uma reflexão sobre a educação e suas formas, seus sujeitos e espaços, bem como articular discussões sobre diversidade e relações sociais.

\title{
IV.5 O Eixo Articulador Iniciação à Docência: Estágio Supervisionado (ES)
}

O ES é o momento da formação inicial em que a escola passa a figurar para o licenciando como seu futuro campo de trabalho, já que o professor é o profissional que sempre esteve na escola, seja como estudante seja como profissional docente (NÓVOA, 2014). Na história da formação de professores, a ideia de aplicação na escola (local da prática) da teoria aprendida na universidade ganhou força de lei no início da década de 1960 com a criação das escolas de aplicação. De acordo com Goulart (2002),

\begin{abstract}
da necessidade de preparar o futuro professor para a parte pedagógica surgiu a ideia de uma prática de ensino durante o período de formação, associada a um estágio durante o qual o aluno [licenciando] entraria em contato com uma turma e poderia acompanhar um processo real de ensino e aprendizagem, nas escolas de aplicação, verdadeiros laboratórios de pesquisa em ensino (p. 78).
\end{abstract}

Assim, de alguma forma, parece ainda permanecer presente a perspectiva tecnicista e aplicacionista da relação teoria e prática apesar de diversas modificações nas legislações relativas ao ES.

As mais recentes modificações no ES consistem basicamente no aumento da carga horária, chegando a um total 400 horas, com as novas diretrizes e resoluções de 2001 e 2002.

Por outro lado, Silva e Villani (2017) apontam dois elementos que indicam alguma mudança de concepção de ES na legislação: a resolução de 2015 impede a redução de carga horária de ES para aqueles licenciandos que já atuam como professores da educação básica, promovendo assim, uma valorização da formação profissional do professor; bem como um 
maior protagonismo da escola e do professor da educação básica como coformadores, verificados pela inserção de novos indicadores no IA dos cursos de graduação (BRASIL, 2017).

O ES do currículo antigo estava organizado em duas etapas: (i) o estágio integrado, como parte das disciplinas de Oficina de Projetos em Ensino (de Eletromagnetismo e de Ótica e Física Moderna, no quinto e sexto períodos respectivamente), com 135 horas; (ii) residência escolar e codocência (CEFET/RJ, 2013), no formato das disciplinas de Prática de Ensino e Estágio Supervisionado I e II, com total de 270 horas, realizadas no sétimo e oitavo períodos, respectivamente.

Mesmo no currículo antigo, a nossa compreensão de ES "como um campo de conhecimento, o que significa atribuir-lhe um estatuto epistemológico que supera a tradicional redução à atividade prática instrumental" (PIMENTA; LIMA, 2005/06, p. 6), proporcionou uma organização tal que as práticas desenvolvidas pelos licenciandos no contexto da escola de educação básica nunca ficassem sem as discussões e reflexões teóricas devidas. Dessa forma, as disciplinas que tinham carga horária de ES contavam com pelo menos dois tempos de aula na universidade para reflexão, em alguns casos com a presença do professor supervisor da escola parceira. No entanto, na perspectiva dos avaliadores do MEC, as horas deveriam ser cumpridas apenas na sala de aula da escola da educação básica.

Outro problema do currículo antigo era a implementação do estágio na modalidade integrada, isto é, nas disciplinas de Oficina de Projeto de Ensino de Eletromagnetismo e de Ensino de Ondulatória e Física Moderna, o estágio deveria estar relacionado ao ensino desses conteúdos a partir do desenvolvimento de projetos de ensino e aprendizagem. Porém, havia uma dificuldade de articulação com as escolas, pois o conteúdo da escola nem sempre correspondia aos da disciplina. Esses problemas eram mais evidentes nas disciplinas Oficina de Física Ondulatória e Moderna, pois os conteúdos de Física Moderna nem sempre estavam presentes. Como vamos apresentar a seguir, a solução foi a criação das disciplinas de Oficinas de Projeto de Ensino (Mecânica, etc) no formato de PCC para dar conta da problematização e do aprendizado do ensino desses conteúdos ao invés de fazê-los como ES.

Os problemas apontados nos parágrafos acima, as críticas dos avaliadores do MEC e as mudanças nas DCN para formação de professores foram importantes para as mudanças na estrutura do ES. No geral, as mudanças incluem (i) uma melhor distribuição das horas de ES em cinco períodos, um a mais em relação a currículo antigo; (ii) tempos de aulas para reflexão e discussão não são contados como horas de ES, e (iii) a inserção da gestão escolar, ensino fundamental, EJA e educação especial como modalidade de estágios.

A distribuição da carga horária é apresentada no Quadro 5, conforme consta no PPC do Curso (CEFET/RJ, 2016). 
Quadro 5 - Estrutura e distribuição da carga horária de Estágio Supervisionado na nova versão curricular do Curso de Licenciatura em Física do CEFET/RJ campus Petrópolis.

\begin{tabular}{|c|c|c|c|}
\hline Prática Docente & Estágio Supervisionado & Período & $\begin{array}{c}\text { Carga } \\
\text { horária (h) }\end{array}$ \\
\hline Pratica Docente I & Estrutura e Gestão Escolar & $5^{\circ}$ & 45 \\
\hline Prática Docente II & Inclusão/ Educação Especial & $6^{\circ}$ & 60 \\
\hline Prática Docente III & $\begin{array}{c}\text { Ensino de Ciências no Ensino Fun- } \\
\text { damental }\end{array}$ & $7^{\circ}$ & 100 \\
\hline Prática Docente IV & EJA/ Docência & $8^{\circ}$ & 105 \\
\hline Prática Docente V & Docência & $9^{\circ}$ & 90 \\
\hline & Total & & 400 \\
\hline
\end{tabular}

A nova estrutura do ES apresentada no Quadro 5 busca uma superação do modelo tecnicista no aprendizado da prática profissional do professor. Um exemplo é a própria troca dos nomes das disciplinas para Prática Docente ao invés de Prática de Ensino, como é mais comumente encontrado nos cursos de formação de professores. A nossa compreensão de docência não é a atividade de ensino, fundamentado na simples aplicação da teoria, mas ao contrário, "a docência também comporta diversas ambiguidades, diversos elementos 'informais', indeterminados, incertezas, imprevistos" (TARDIF; LESSARD, 2007; p. 43 apud TRACTEMBERG, 2011, p. 123). De forma geral, a docência implica em atividades com e para os alunos, mas também implica em atividades com ou para os colegas de profissão, atividades relacionadas à sua própria formação e seu desenvolvimento profissional, bem como atividades relacionadas à organização escolar (TRACTENBERG, 2011). Portanto, em cada semestre de ES, o licenciando terá a oportunidade de se desenvolver em cada uma das atividades que compõem a docência, como mostrado no Quadro 5.

Por fim, a Prática Docente IV e a V objetivam que o licenciando desenvolva atividades de docência com seus colegas de estágio ou com o supervisor, em um sistema de codocência, previsto no PPC do Curso: "A codocência permite aos atores envolvidos captarem as múltiplas dimensões do processo educativo e formativo que se constitui durante a disciplina de estágio, proporcionando inclusive a formação continuada do professor supervisor e do professor da disciplina de Prática Docente" (CEFET/RJ, 2016, p. 48-49).

\section{IV.6 O Eixo Articulador Iniciação à Docência: as disciplinas de Oficina de Projetos de Ensino (OPE)}

As disciplinas de OPE constituem espaços de articulação entre conteúdos específicos e pedagógicos presentes desde a primeira versão curricular do curso em 2008. Inicialmente 
pensadas para abrigar o laboratório formal de física, esse espaço curricular foi reinterpretado pelo corpo docente ao longo do processo de consolidação do curso como aquele adequado à PCC. Essas disciplinas eram atreladas a uma área de conhecimento da física, oferecidas sempre no semestre sequencial ao que o aluno cursa sua versão teórica. Por exemplo, se em um semestre o aluno cursava a disciplina teórica de Mecânica, no semestre seguinte cursaria a OPE em Mecânica e assim da mesma forma com a Física Térmica, o Eletromagnetismo e a Física Ondulatória e Moderna.

Na versão antiga do currículo, esses espaços se consolidaram como privilegiados para discutir a didática específica sobre o tema da física em questão e para a construção de projetos de ensino concretos aplicados e/ou aplicáveis a educação básica. Além dessas funções, como dito anteriormente, essas disciplinas deveriam dar conta de cobrir a parte experimental do conteúdo correlato de física e ainda possuíam uma carga horária de ES.

A nova versão das OPE foi desenhada unicamente para consolidar um espaço de construção de projetos de ensino. Às disciplinas de OPE também cabem a exploração da construção de experimentos (inclusive com materiais de baixo custo) de forma atrelada aos projetos de ensino. Outros aspectos importantes da didática específica das ciências são também condutores dessas disciplinas, tais como a História e a Filosofia da Ciência, a abordagem Ciência Tecnologia e Sociedade (CTS), a exploração de conceitos prévios, dentre outras.

Outra mudança importante é a retirada da carga horária de ES desse espaço curricular. Como apontado na seção anterior, essa articulação entre os projetos de ensino e a escola básica, que é teoricamente interessante, se mostrou pouco efetiva em sua implementação anterior, pois o conteúdo de física debatido no curso superior nem sempre casava com aquele da escolaridade básica. É muito difícil realizar essa conexão com a escola básica levando em consideração conteúdos pré-determinados em ambos os espaços.

Dessa maneira, as OPE se tornaram, por excelência, espaços para execução das PCC, no sentido de ser um espaço que pensa a escola e suas questões, mas tendo caráter diferenciado do ES. A função principal desse espaço no currículo é fazer a tão necessária e desejável articulação entre os conteúdos específicos da física e os conteúdos pedagógicos.

Além disso, essas disciplinas também envolvem um caráter de extensão e de pesquisa, visto que os projetos de ensino produzidos podem ser levados à sala de aula da escola básica, gerando uma integração universidade-escola e oferecendo possibilidades de pesquisa sobre a prática.

\section{IV.7 As atividades formativas sobre as questões de inclusão e educação ambiental}

O PNE de 2014 apresenta como uma de suas diretrizes a superação das desigualdades educacionais, com ênfase na promoção da cidadania e na erradicação de todas as formas de discriminação (artigo III) e promoção dos princípios do respeito aos direitos humanos, à diversidade e à sustentabilidade socioambiental (artigo X). 
A Resolução CNE/CP 02/2015 também aborda o assunto em seu artigo 12, que trata dos núcleos formativos. No núcleo 1, alínea i está descrito que a "pesquisa e estudo das relações entre educação e trabalho, educação e diversidade, direitos humanos, cidadania, educação ambiental, entre outras problemáticas centrais da sociedade contemporânea" deverão ser explorados nos cursos de licenciatura de forma articulada e interdisciplinar.

Na busca pelo cumprimento do estabelecido no PNE e pelas DCN e na consolidação de uma escola de qualidade, inclusiva com base nos direitos humanos, torna-se de extrema urgência ampliar as discussões sobre o estabelecido nos artigos III e X nos cursos de formação de professores. No intuito de ampliar estas discussões, o NDE discutiu amplamente as questões apontadas pelo PNE e outras legislações, pois, para o grupo de docentes do núcleo não bastava apenas a inserção de disciplinas que contemplassem tais áreas, mas era necessário tratar as questões de inclusão, relações étnico-raciais e educação socioambiental de forma transversal, ou seja, era necessário que as demais disciplinas do currículo abordassem de alguma forma estas temáticas. Porém, para além da forma transversal, foi um consenso a permanência da disciplina Libras, no quinto período, que visa instrumentalizar o aluno para o trabalho com a Língua Brasileira de Sinais e discutir questões específicas da inclusão educacional das pessoas com necessidades educacionais especiais. Para assegurar essa discussão e, ainda, a devida articulação no que concerne a prática docente do futuro professor de física foi incluída no nono período a disciplina "Oficina de Projeto de Ensino de Física em Modalidades Especiais". Essa disciplina constitui o bloco integrador do curso e totaliza as horas de PCC.

No sexto período, a disciplina de Ciência e Meio ambiente visa atender ao demandado pela legislação. Ela apresenta em sua ementa discussões sobre educação ambiental e gestão de resíduos, aproximando assim a questão ambiental à temática da formação específica dos licenciados em Física.

Como forma de articular as discussões já abordadas acima, no nono período, os licenciandos cursarão ainda a disciplina de Sujeito, Sociedade e Cultura. Esta disciplina tem por finalidade abordar de forma integrada as discussões sobre diversidade, relações étnicoraciais e educação socioambiental, proporcionando aos alunos uma visão de sociedade inclusiva e sustentável.

Ao abordarmos estas questões no novo currículo, buscamos, para além do cumprimento do previsto na legislação, a formação de um sujeito que seja capaz de pensar de forma crítica sobre a realidade na qual está inserido e, sobretudo, de analisar o contexto sociocultural e ambiental no qual exercerá sua profissão, tendo como base de ação o respeito aos direitos humanos.

\section{IV.8 Eixo Articulador Extensão e Pesquisa: a disciplina Práticas Extensionistas}

O PNE, através da estratégia 12.7 da meta 12, prevê que, até 2020, os cursos superiores devem "assegurar, no mínimo, $10 \%$ (dez por cento) do total de créditos curriculares exigi- 
dos para a graduação em programas e projetos de extensão universitária, orientando sua ação, prioritariamente, para áreas de grande pertinência social" (BRASIL, 2014). Essa indicação do PNE busca aproximar mais a universidade da comunidade, estreitando os laços entre ambas e construindo parcerias importantes para a construção e divulgação do conhecimento.

A extensão universitária é uma atividade acadêmica, articulada de forma indissociável ao ensino e à pesquisa, que busca o estreitamento dos laços entre universidade e sociedade a partir de um processo educativo, cultural e científico. O Fórum de Pró-reitores de Extensão conceitua a extensão como "um processo interdisciplinar educativo, cultural, científico e político que promove a interação transformadora entre universidade e outros setores da sociedade" (FORPROEX, 2010, p. 125).

No intuito de consolidar as atividades extensionistas e articulá-las com as atividades de ensino de modo a promover o estreitamento de laços entre o nosso curso e as comunidades que cercam a instituição, optamos por apresentar na estrutura do PPC uma disciplina específica que trata das práticas extensionistas, no sexto período, que representa uma carga horária de 27 horas. Além disso, o curso possui as disciplinas de OPE que, em essência, se configuram como espaços integradores para as práticas extensionistas, através da culminância dos projetos de ensino nas salas de aula da educação básica, contabilizando para o total de créditos envolvendo a extensão universitária no curso.

Vale ressaltar que esta é a primeira tentativa de consolidar o previsto na estratégia 12.7 do PNE. Como a extensão universitária ainda não ocupa lugar de destaque no meio universitário, pensar sua articulação com o sistema de créditos é uma tarefa difícil, sobretudo porque não partimos da ideia de uma extensão unicamente assistencialista e que não se articule verdadeiramente com a formação dos futuros professores. A discussão sobre a concretização da estratégia é apenas inicial e um dos pontos que estamos tentando aprofundar é sua articulação direta ao ES.

\section{IV.9 Currículo antigo versus Currículo novo}

Como síntese das mudanças implementadas construímos o quadro 6, no qual constam algumas disciplinas antigas e as novas correspondentes por Eixo Articulador, bem como comentários comparativos. Pretendemos, a partir dessa síntese, ressaltar alguns pontos nevrálgicos nos quais o currículo novo se diferencia do antigo. 
Quadro 6 - Quando comparativo entre o currículo antigo e o novo.

\begin{tabular}{|c|c|c|c|}
\hline Eixo & $\begin{array}{c}\text { Currículo Antigo } \\
\text { (Disciplina/ Perío- } \\
\text { do) }\end{array}$ & $\begin{array}{c}\text { Currículo Novo (Disciplina/ } \\
\text { Período) }\end{array}$ & Comentários \\
\hline $\begin{array}{l}\text { Formação } \\
\text { Específica }\end{array}$ & $\begin{array}{l}\text { - Cálculo I/ } 1 \\
\text { - Vetores e Geom. } \\
\text { Analítica/ } 1 \\
\text { - Introdução à Físi- } \\
\text { ca/ } 1 \\
\text { - Cálculo II/ } 2 \\
\text { - Int. à Álg. Linear/ } \\
2 \\
\text { - Mecânica Clássica/ } \\
2 \\
\text { - Lab. de Mec. Clás- } \\
\text { sica/2 } \\
\text { - Cálculo III/ } 3 \\
\text { - Fluidos e Fís. } \\
\text { Térmica/ } 3 \\
\text { - Métodos Mat. } \\
\text { aplic. à Física I/ } 3 \\
\text { - Estatística/ } 4 \\
\text { - Eletromagnetismo } \\
\text { Básico/ } 4 \\
\text { - Métodos Mat. } \\
\text { aplic. à Física II/ } 4 \\
\text { - Fís. Moderna I/ } 5 \\
\text { - Fís. Ondulatória/ } 5 \\
\text { - Mecânica Analíti- } \\
\text { ca/ } 5 \\
\text { - Tópicos de Ele- } \\
\text { tromagnetismo/ } 6 \\
\text { - Física Moderna II/ } \\
6 \\
\text { - Mec. Estatística/ } 7 \\
\text { - Tópicos Aplic. Fís. } \\
\text { Contemporânea/ } 8 \\
\text { a }\end{array}$ & $\begin{array}{l}\text { - Int. à Física/ } 1 \\
\text { - Int. à Astronomia/ } 1 \\
\text { - Int. às Ciências Experimentais/ } \\
1 \\
\text { - Funções/ } 1 \\
\text { - Computação Algébrica/ } 1 \\
\text { - Matrizes e Vetores/ } 1 \\
\text { - Mecânica Básica I/ } 2 \\
\text { - Geom. Analítica/ } 2 \\
\text { - Cálculo I/ } 2 \\
\text { - Mecânica Básica II/ } 3 \\
\text { - Física Térmica/ } 3 \\
\text { - Probabilidade e Estatística/ } 3 \\
\text { - Cálculo II/ } 3 \\
\text { - Eletromagnetismo Básico/ } 4 \\
\text { - Circuitos elétricos e eletrôni- } \\
\text { cos/ } 4 \\
\text { - Álgebra Linear/ } 4 \\
\text { - Cálculo III/ } 4 \\
\text { - Física Ondulatória e Óptica/ } 5 \\
\text { - Relatividade/ } 5 \\
\text { - Cálculo IV/ } 5 \\
\text { - Física Quântica I/ } 6 \\
\text { - Introdução à Física Nuclear/ } 7 \\
\text { - Laboratório de Física Moderna/ } \\
8 \\
\text { - Discussão dos Conceitos de } \\
\text { Física/ } 8\end{array}$ & $\begin{array}{l}\text { O aumento no número de disciplinas } \\
\text { de formação específica se deve ao fato } \\
\text { de terem sido acrescentadas as disci- } \\
\text { plinas introdutórias e ao desmembra- } \\
\text { mento de disciplinas, tais como Me- } \\
\text { cânica Clássica e Cálculo. Nota-se } \\
\text { também a ausência de disciplinas, } \\
\text { como Métodos Matemáticos Aplica- } \\
\text { dos à Física, Mecânica Analítica, } \\
\text { Física Moderna II, Tópicos de Ele- } \\
\text { tromagnetismo, Mecânica Estatística e } \\
\text { Tópicos Aplicados de Física Contem- } \\
\text { porânea, que viraram optativas pelo } \\
\text { seu caráter fortemente ligado ao Ba- } \\
\text { charelado em Física. Foram acrescen- } \\
\text { tadas outras disciplinas de caráter } \\
\text { mais integrador à prática docente, com } \\
\text { apelo direto a temas de interesse para } \\
\text { a educação básica tais como Circuitos } \\
\text { Elétricos e Eletrônicos, Introdução à } \\
\text { Física Nuclear, Discussão dos Concei- } \\
\text { tos da Física e etc. }\end{array}$ \\
\hline $\begin{array}{l}\text { Formação } \\
\text { Pedagógi- } \\
\text { ca }\end{array}$ & $\begin{array}{l}\text { - Fundamentos da } \\
\text { Educação } \\
\text { - Didática Básica } \\
\text { - Plan. e Aval. da } \\
\text { Aprend. } \\
\text { - Pol. Educ. e Form. } \\
\text { de Profs. no Brasil } \\
\text { - Psicologia aplic. à } \\
\text { Educ. }\end{array}$ & $\begin{array}{l}\text { - Educação e Sociedade } \\
\text { - Fundamentos Histórico- } \\
\text { Filosóficos da Educação } \\
\text { - Pol. Públicas e Form. de Pro- } \\
\text { fessores } \\
\text { - Didática } \\
\text { - Psicologia Aplicada a Educa- } \\
\text { ção } \\
\text { - Sujeito, Sociedade e Cultura }\end{array}$ & $\begin{array}{l}\text { A inserção de disciplinas pedagógicas } \\
\text { com caráter reflexivo tenta superar a } \\
\text { ideia de que as disciplinas pedagógi- } \\
\text { cas são apenas campos instrumentais e } \\
\text { espaços de receitas prontas. A criação } \\
\text { da disciplina Educação e Sociedade } \\
\text { abre espaço para reflexões sociológi- } \\
\text { cas e para uma forma mais ampla e } \\
\text { contextualizada de pensar a educação. } \\
\text { A disciplina de Fundamentos Históri- } \\
\text { co-Filosóficos da Educação simulta- } \\
\text { neamente realiza discussões filosófi- } \\
\text { cas e históricas da educação, em espe- } \\
\text { cial da educação brasileira. Na se- } \\
\text { quência, as reflexões teórico-práticas }\end{array}$ \\
\hline
\end{tabular}




\begin{tabular}{|c|c|c|c|}
\hline & & & $\begin{array}{l}\text { são dadas pelas disciplinas de Políti- } \\
\text { cas Públicas e Formação de Professo- } \\
\text { res, Didática e Psicologia Aplicada a } \\
\text { Educação buscando articulação com } \\
\text { as disciplinas específicas. Ao final do } \\
\text { curso, a disciplina Sujeito, Sociedade } \\
\text { e Cultura busca levar a uma reflexão } \\
\text { sobre a educação e suas formas, seus } \\
\text { sujeitos e espaços, bem como articular } \\
\text { discussões sobre diversidade e rela- } \\
\text { ções sociais. }\end{array}$ \\
\hline $\begin{array}{l}\text { Iniciação a } \\
\text { Docência }\end{array}$ & $\begin{array}{l}\text { - Ofic. de Proj. de } \\
\text { Ens. de Mec. } \\
\text { - Ofic. de Proj. de } \\
\text { Ens. de Fís. Térmica } \\
\text { - Ofic. de Proj. de } \\
\text { Ens. de Eletromag- } \\
\text { netismo } \\
\text { - Evolução do Pens. } \\
\text { Cient. } \\
\text { - Ofic. de Proj. de } \\
\text { Ens. de Fís. Ond. e } \\
\text { Moderna } \\
\text { - Prática de Ens. Est. } \\
\text { Superv. I } \\
\text { - Prática de Ens. Est. } \\
\text { Superv. II } \\
\text { - Elem. e Est. p/ } \\
\text { Ens. de Fís. }\end{array}$ & $\begin{array}{l}\text { - Ofic. de Proj. de Ens. de Mec. } \\
\text { - Ofic. de Proj. de Ens. de Fís. } \\
\text { Térmica } \\
\text { - Elem. e Est. p/ Ens. de Fís. } \\
\text { - Ofic. de Proj. de Ens. de Ele- } \\
\text { tromagnetismo } \\
\text { - Ofic. de Proj. de Ens. de Fís. } \\
\text { Ond. e Moderna } \\
\text { - Prática Docente I } \\
\text { - Prática Docente II } \\
\text { - Prática Docente III } \\
\text { - Prática Docente IV } \\
\text { - Prática Docente V }\end{array}$ & $\begin{array}{l}\text { A nova versão das OPE foi desenhada } \\
\text { unicamente para consolidar um espaço } \\
\text { de construção de projetos de ensino, } \\
\text { no qual se incorporam as discussões e } \\
\text { reflexões presentes na disciplina de } \\
\text { elementos e estratégias do currículo } \\
\text { antigo. Não estão presentes dentro das } \\
\text { OPE horas de estágio como na versão } \\
\text { antiga. No entanto as OPE são consi- } \\
\text { deradas espaços de extensão por exce- } \\
\text { lência, pois os projetos são levados de } \\
\text { fato para sala de aula, reforçando a } \\
\text { indissociabilidade entre teoria e práti- } \\
\text { ca. } \\
\text { As horas de estágio se encontram } \\
\text { todas contidas nas disciplinas de prá- } \\
\text { tica docente, que se organizam por } \\
\text { temas, entendendo que a atividade } \\
\text { docente é algo mais amplo que as } \\
\text { práticas de sala de aula. }\end{array}$ \\
\hline
\end{tabular}

\section{Considerações finais: As limitações da proposta do novo currículo}

Diante de todas as dificuldades mapeadas durante o período de execução do Currículo Antigo e toda a reflexão que daí emergiu, é necessário apontar algumas limitações da nova proposta.

Goodson (2008) destaca a importância dos professores, de suas missões pessoais e histórias de vida na realização de um currículo. Para esse autor, o sucesso ou o fracasso de uma inovação curricular está profundamente relacionado com os professores que são os verdadeiros protagonistas da mudança. Assumindo essa perspectiva, é preciso pontuar que a nova proposta curricular aqui apresentada é uma proposta possível. Corroborando a análise de Camargo (2007), podemos falar que essa foi a mudança curricular possível de ser colocada em prática pelo grupo de docentes que leciona no Curso de Licenciatura em Física do CEFET/RJ campus Petrópolis.

As muitas discussões, estudos e todos os levantamentos realizados pelo grupo de professores que trabalhou na mudança curricular refletem os obstáculos que esse grupo se vê capaz de superar. Trata-se de um grupo bastante heterogêneo, com histórias de vida distintas. 
O acordo que se firma na forma final do documento é o resultado de negociações, presenças e ausências.

Apesar da organização por Eixos Articuladores, como propõe a Resolução CNE/CP 02/2015, não foi possível superar a forma disciplinar da matriz curricular. Embora muito se tenha trabalhado para superar a fragmentação existente no currículo disciplinar, buscando articular conteúdos e disciplinas, a articulação se dá sobre algo que continua a ser fragmentado.

As disciplinas de Física continuam muito naturalizadas no currículo. Não foi possível introduzir formatos muito inovadores rompendo com as seleções e sequências tradicionais dos conteúdos de Física. É como se, ao fazer isso, se descaracterizasse a própria Física. Uma mudança mais radical poderia trazer muito incômodo aos professores mais tradicionais e prejudicar o andamento do Currículo Novo. Assim, optou-se por manter muitas disciplinas no formato curricular tradicional, que expressam o sentimento de que "a Física é assim".

Mesmo nas disciplinas pedagógicas e integradoras, o desafio prático de procurar formas não disciplinares é de difícil superação, tanto pelas práticas arraigadas dos professores quanto pela estrutura burocrática da universidade e pela própria limitação dos espaços físicos.

A prática de aulas expositivas também continua sendo o modo predominante a despeito de se pensarem espaços para que os alunos sejam mais ativos e menos passivos em sala de aula. Há uma preocupação dos docentes em geral em relação ao conteúdo que será abordado. Atividades que não passam pela exposição de conteúdos muitas vezes são encaradas como "perda de tempo". Isso também impediu o projeto de curso de incorporar metodologias de resolução de exercícios em grupo e outros tipos de atividades como práticas curriculares formais.

Ademais, é preciso ressaltar que as mudanças aqui apresentadas são ainda uma prescrição, que precisará ser muito analisada do ponto de vista da prática, para que possamos ver em que medida o currículo prescrito se tornará um currículo vivenciado (SILVA, 2010). Serão necessárias ainda outras tantas pesquisas para correlacionar as práticas do curso com as reais implicações para a formação docente de professores de física.

\section{Agradecimentos}

Os autores agradecem a todo o corpo docente do Curso de Licenciatura em Física do CEFET/RJ campus Petrópolis pelas contribuições ao longo do processo de reestruturação curricular, em especial aos professores que fizeram parte da Comissão de Reformulação, que, de certa forma, são autores de várias das ideias apresentadas nesse trabalho, bem como aos licenciandos que participaram de parte das discussões iniciais. Agradecemos também aos diversos setores de apoio acadêmico do campus na revisão do trabalho, tais como a Seção de Articulação Pedagógica, a Biblioteca, a Gerência Acadêmica, o Setor de Psicologia e a Secretaria Acadêmica, assim como à Direção e ao Conselho de Ensino do CEFET/RJ e aos membros do 
Conselho do Campus (CONPUS) Petrópolis pelas análises e aprovações do documento em âmbito institucional.

\section{Referências bibliográficas}

ALMEIDA, B. J.; SCHIMIGUEL, J. Avaliação sobre as causas da evasão escolar no ensino superior: estudo de caso no curso de licenciatura em física no Instituto Federal do Maranhão. Revista de Ensino de Ciências e Matemática, v. 2, n. 2, p.167-178, jul/dez 2011.

ANDRADE, A. C.; DINIZ, L. G.; CAMPSO, J. C. C. Uma Metodologia de Ensino para Disciplinas de Laboratório Didático. Revista Docência do Ensino Superior, v. 1, 2011.

ARAÚJO, R. S.; VIANNA, D. M. Aspectos históricos da remuneração dos professores de física do Brasil e da carência deste profissional na educação básica frente à realidade da OECD. In: SIEF 9, 2008, Rosário. Atas...

ATAÍDE, J. S. P. de; LIMA, L. M.; ALVES, E. O. A evasão escolar e a repetência no curso de Licenciatura em Física: um estudo de Caso. In: SIMPÓSIO NACIONAL DE ENSINO DE FÍSICA, XVII, 2007, São Luiz, MA.

BARCELLOS, M. E.; LEITE, F. G.; WANIS, R. Introdução à Física: Possibilidades e Perspectivas. Revista Tecnologia e Cultura, Rio de Janeiro, ano 12, n. 16, p. 14/21, jan./jun. 2010.

BARCELLOS, M. E. Conhecimento físico e currículo: problematizando a licenciatura em física. 2013. Tese (Doutorado) - Instituto de Física, USP.

BARCELLOS et al. A reforma do ensino médio e as desigualdades no Brasil. Revista Brasileira de Educação Profissional e Tecnológica, v. 2, n. 13, 2017, p. 118-136.

BARROSO, M. F.; FALCÃO, E. B. M. Evasão Universitária: o caso do Instituto de Física da UFRJ. In: ENCONTRO DE PESQUISA EM ENSINO DE FÍSICA, IX, 2004, Jaboticatubas, MG. Disponível em:

$<$ http://www.sbf1.sbfisica.org.br/eventos/epef/ix/sys/resumos/ T0132-2.pdf>.

BRASIL. Casa Civil. Lei n ${ }^{\circ} 13.005$, de 25 de junho de 2014. Aprova o Plano Nacional de Educação - PNE e dá outras providências. Brasília, DF: Casa Civil, 2014. Disponível em: $<$ http://www.planalto.gov.br/ccivil_03/_ato2011-2014/2014/ lei/113005.htm>.

BRASIL. Conselho Nacional de Educação. Parecer CNE/CP nº 02, de 2 de julho de 2015. Dá nova redação ao item 3.6, alínea c, do Parecer CNE/CP 9/2001, que dispõe sobre as Diretrizes Curriculares Nacionais para a Formação de Professores da Educação Básica, em nível superior, curso de licenciatura, de graduação plena. 
BRASIL. Conselho Nacional de Educação. Parecer CNE/CES nº 1304, de 6 de novembro de 2001, que dispõe sobre as Diretrizes Curriculares Nacionais para os Cursos de Física. Disponível em: <http://portal.mec.gov.br/cne/arquivos/pdf/CES1304.pdf>. Acesso em: 28 nov. 2017.

BRASIL. Conselho Nacional de Educação. Resolução CNE/CP n ${ }^{\circ}$ 1, de 18 de fevereiro de 2002. Institui Diretrizes Curriculares Nacionais para a Formação de Professores da Educação Básica, em nível superior, curso de licenciatura, de graduação plena. Disponível em: <http://portal.mec.gov.br/cne/arquivos/pdf/rcp01_02.pdf>. Acesso em: 28 nov. 2017.

BRASIL. Conselho Nacional de Educação. Resolução CNE/CP n ${ }^{\circ}$ 2, de 19 de fevereiro de 2002. Institui a duração e a carga horária dos cursos de licenciatura, de graduação plena, de formação de professores da Educação Básica em nível superior. Disponível em: <http://portal.mec.gov.br/cne/arquivos/pdf/CP022002.pdf>. Acesso em: 28 nov. 2017.

BRASIL. Conselho Nacional de Educação. Resolução CNE/CP n ${ }^{\circ}$ 1, de $1^{\circ}$ de julho de 2015. Define as Diretrizes Curriculares Nacionais para a formação inicial em nível superior (cursos de licenciatura, cursos de formação pedagógica para graduados e cursos de segunda licenciatura) e para a formação continuada. Disponível em: <http://portal.mec.gov.br/index .php?option=com_docman\&view=download\&alias=17719-res-cne-cp-002-

03072015\&category_slug=julho-2015-pdf\&Itemid=30192>. Acesso em: 28 nov. 2017.

BRASIL. Conselho Nacional de Educação. Resolução CNE/CP nº 2, de $1^{\circ}$ de julho de 2015. Define as Diretrizes Curriculares Nacionais para a formação inicial em nível superior (cursos de licenciatura, cursos de formação pedagógica para graduados e cursos de segunda licenciatura) e para a formação continuada. Disponível em: <http://portal.mec.gov.br/index. php?option=com_docman\&view=download\&alias=17719-res-cne-cp-002-

03072015\&category_slug=julho-2015-pdf\&Itemid=30192>. Acesso em: 28 nov. 2017.

BRASIL. Lei 9.394, de 20 de dezembro de 1996. Estabelece as Diretrizes e Bases da Educação Nacional. Disponível em: <http://www.planalto.gov.br/ccivil_03/leis/L9394.htm>. Acesso em: 28 nov. 2017.

BRASIL. Lei 11.892, de 29 de dezembro de 2008. Institui a Rede Federal de Educação Profissional, Científica e Tecnológica, cria os Institutos Federais de Educação, Ciência e Tecnologia, e dá outras providências. Disponível em: <http://www.planalto.gov.br/ccivil_03/_ ato2007-2010/2008/lei/111892.htm>. Acesso em: 28 nov. 2017.

BRASIL. Lei 13.005, de 25 de junho de 2014. Aprova o Plano Nacional de Educação 2014/2024. Disponível em: <http://www.planalto.gov.br/ccivil_03/_ato2011-2014/2014/lei/ 113005.htm>. Acesso em: 28 nov. 2017. 
BRASIL. Ministério da Educação. Instrumento de Avaliação de Cursos de Graduação presencial e a distância, 2017.

CAMARGO, S. Discursos presentes em um processo de reestruturação curricular de um Curso de Licenciatura em Física: o legal, o real e o possível. 2007. 285f. Tese (Doutorado em Educação para a Ciência) - Faculdade de Ciências, UNESP, Bauru.

CARVALHO, A. M. P. Reformas nas licenciaturas: a necessidade de uma mudança de paradigma mais do que de mudança curricular. Em Aberto, Brasília, ano 12, n. 54, abr./jun. 1992.

CEFET/RJ. Centro Federal de Educação Tecnológica do Rio de Janeiro - Celso Suckow da Fonseca- Projeto Pedagógico do Curso de Licenciatura em Física Petrópolis, 2013.

CEFET/RJ. Centro Federal de Educação Tecnológica do Rio de Janeiro - Celso Suckow da Fonseca- Projeto Pedagógico do Curso de Licenciatura em Física Petrópolis, 2016. Disponível em: <http://www.cefet-rj.br/index.php/licenciatura-fisica-petropolis>. Acesso em: 28 nov. 2017.

CIAVATTA, M. O Ensino Integrado, a Politecnia e a Educação Omnilateral. Por Que Lutamos? Revista Trabalho \& Educação, v. 23, n. 1. p. 187-205, 2014.

DOURADO, L. F. Diretrizes Curriculares Nacionais para a Formação inicial e Continuada dos Profissionais do Magistério da Educação Básica: concepções e desafios. Educação e Sociedade, Campinas, SP, v. 36, n. 131, p. 299-324, abr./jun. 2015.

LEITE, L.; ESTEVES, E. Análise crítica de actividades laboratoriais: Um estudo envolvendo estudantes de graduação. Revista Electrónica de Enseñanza de las Ciencias, v. 4, n. 1, 2005 .

FEIX, E. C.; SARAIVA, S. B.; KIPPER, L. M. A Importância da Física Experimental no Processo Ensino-Aprendizagem. Salão de Ensino e de Extensão, 2012.

FEYNMAN, R. Deve ser Brincadeira, sr. Feynman! Brasília: UNB, 2000.

FÓRUM DE PRÓ-REITORES DE EXTENSÃO DAS UNIVERSIDADES PÚBLICAS BRASILEIRAS. Indissociabilidade Ensino-Pesquisa-Extensão e a Flexibilização Curricular: uma visão da extensão. Porto Alegre: UFRGS; Brasília: MEC/SESU, 2006. (Coleção Extensão Universitária, v. 4).

GATTI, B. Formação de Professores no Brasil: características e problemas. Educação e Sociedade, v. 31, n. 113, Campinas, 2010, p. 1355-1379.

GOULART, S. M. A prática de ensino na formação de professores: uma questão (dês) conhecida. Revista da Universidade Rural, Série Ciências Humanas, v. 24, n 1-2, p. 77-87, 2002.

GOODSON, I. F. As Políticas de Currículo e de Escolarização. Petrópolis: Vozes, 2008. 
GRIZONY A.; SILVA F. B. S. Um estudo sobre evasão no curso de licenciatura em Física do CEFET/RJ. 2014. Monografia - Universidade Federal de Juiz de Fora.

INEP/MEC. Sinopse do Censo dos Profissionais do Magistério da Educação Básica - 2003. Brasília: MEC, 2006.

JUNIOR A. G. B.; SOUZA, R. R. Estudo da evasão no curso de licenciatura em física do CEFET-GO. In: ENCONTRO NACIONAL DE PESQUISA E EDUCAÇÃO EM CIENCIAS, VI, 2007, Bauru, SP. Disponível em: <http://www.fep.if.usp.br/ profis/arquivos/vienpec/ CR2/p133.pdf>. Acesso em: 11 dez. 2017.

LOPES, A. C. Competências na organização curricular da reforma do ensino médio. Boletim Técnico do Senac, Rio de Janeiro, v. 27, n. 3, p. 1-20, 2001.

MALDANER, O. A. A formação inicial e continuada de professores de Química: professores/pesquisadores. 2. ed. Ijuí: Unijuí, 2003, 424p.

MIZUKAMI, M. G. N. Escola e aprendizagem da docência: processos de investigações e formação. São Carlos-SP: EdUFSCar, 2002.

NÓVOA, A. Profissão Professor. 2. ed. Porto: Porto Editora, 2014.

PIMENTA, S. G; LIMA, M. S. L. Estágio e docência: diferentes concepções. Revista Poíesis, v. 3, n. 3-4, p. 5-24, 2005/06.

PINHEIRO, D. M.; NETO, O. M.; MONTONI, S. “Teoria ou prática: o que abordar primeiro numa disciplina de física?" - uma experiência didática num curso de graduação. In: SIMPÓSIO NACIONAL DE ENSINO DE FÍSICA, XVIII, 2009.

RAMOS, M. N. O Ensino Médio ao longo do século XX: Um projeto inacabado. In: STEPHANOU, M.; BASTOS, M.H.C. (Org.) História e Memórias da Educação no Brasil. Petrópolis: Editora Vozes, 2005.

SILVA, F. A.; KAWAMURA, M. R. Cursos de Licenciatura em Física: Uma revisão sobre os estudos de evasão. In: SIMPÓSIO NACIONAL DE ENSINO DE FÍSICA, XIX, 2011.

SILVA, G. S. F. ; VILLANI, A. Análise de uma disciplina em práticas de ensino de Física na perspectiva da teoria histórico-cultural da atividade. Alexandria, n. 10, v. 2, 2017, p. 3-34.

SILVA. T. T. Documentos de identidade, uma introdução às teorias do currículo. Belo Horizonte: Autêntica, 2010.

SOUZA, C. A.; SALEM, S.; KAWAMURA, M. R. Um panorama da evasão e dos concluintes do curso de licenciatura em Física na USP: 1997-2007. In: SIMPÓSIO NACIONAL DE ENSINO DE FÍSICA, XVIII, 2009. 
TARDIF, M.; LESSARD, C. O trabalho docente: elementos para uma teoria da docência como profissão de interações humanas. 3. ed. Petrópolis: Vozes, 2007.

TRACTENBERG, L, F. Colaboração docente e ensino colaborativo na educação superior em ciências, matemática e saúde - contexto, fundamentos e revisão sistemática. 2011. Tese (Doutorado) - Universidade Federal do Rio de Janeiro, Núcleo de Tecnologia Educacional para a Saúde, Rio de Janeiro.

UIBSON J.; ARAUJO R. S.; VIANNA, D. M. Estudo sobre o curso de Licenciatura emFísica: o que dizem os dados estatísticos. Revista Scientia Plena, 2014. 
Anexo 1: Fluxograma da nova versão curricular do Curso de Licenciatura em Física do CEFET/RJ campus Petrópolis

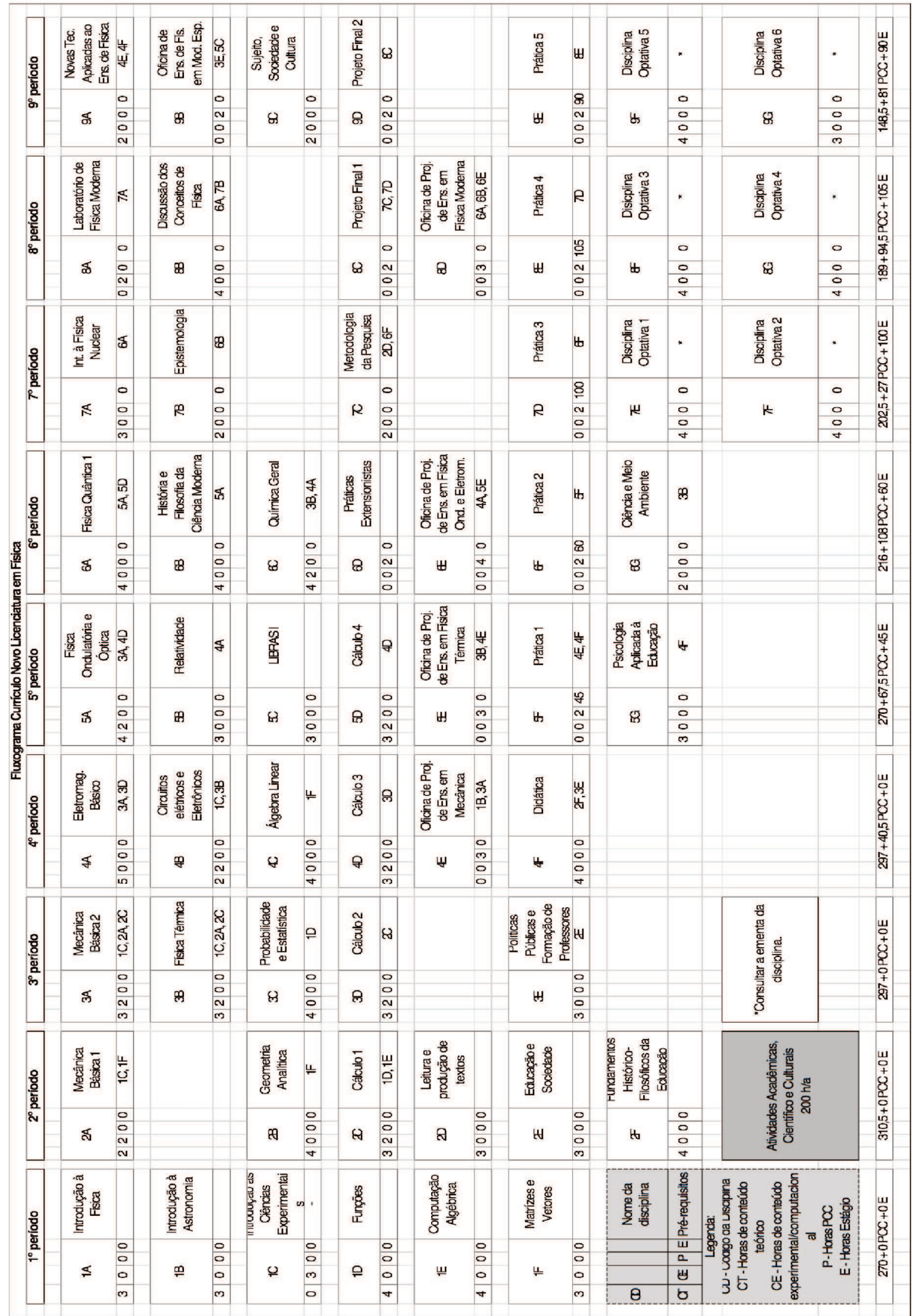


Anexo 2: Matriz curricular resumida do Currículo Antigo do Curso de Licenciatura em Física do CEFET/RJ separada em disciplinas de conhecimento específicos, pedagógicos e de integração ou interdisciplinares

\begin{tabular}{|c|c|c|}
\hline \multicolumn{3}{|c|}{ Disciplinas } \\
\hline Específicas & Pedagógicas & Interdisciplinares \\
\hline & $1^{\circ}$ período & \\
\hline Cálculo I & \multirow{3}{*}{ Fundamentos da Educação } & \multirow{3}{*}{ Comunicação e Linguagem } \\
\hline Vetores e Geom. Analítica & & \\
\hline Introdução à Física & & \\
\hline \multicolumn{3}{|c|}{$2^{\circ}$ período } \\
\hline Cálculo II & \multirow{4}{*}{ Didática Básica } & \multirow{4}{*}{-} \\
\hline Int. à Álg. Linear & & \\
\hline Mecânica Clássica & & \\
\hline Lab. de Mec. Clássica & & \\
\hline \multicolumn{3}{|c|}{$3^{\circ}$ período } \\
\hline Cálculo III & \multirow{3}{*}{ Plan. e Aval. da Aprend. } & \multirow{3}{*}{ Ofic. de Proj. de Ens. de Mec. } \\
\hline Fluidos e Fís. Térmica & & \\
\hline Métodos Mat. aplic. à Física I & & \\
\hline \multicolumn{3}{|c|}{$4^{\circ}$ período } \\
\hline Estatística & \multirow{3}{*}{$\begin{array}{l}\text { Pol. Educ. e Form. de Profs. no } \\
\text { Brasil }\end{array}$} & Ofic. de Proj. de Ens. de Fís. Térmica \\
\hline Eletromagnetismo Básico & & \multirow{2}{*}{ Int. à Ciência da Comp. } \\
\hline Métodos Mat. aplic. à Física II & & \\
\hline \multicolumn{3}{|c|}{$5^{\circ}$ período } \\
\hline Fís. Moderna I & \multirow{3}{*}{-} & Elem. e Est. p/ Ens. de Fís. \\
\hline Fís. Ondulatória & & $\begin{array}{c}\text { Ofic. de Proj. de Ens. de Eletromag- } \\
\text { netismo }\end{array}$ \\
\hline Mecânica Analítica & & LIBRAS \\
\hline \multicolumn{3}{|c|}{$6^{\circ}$ período } \\
\hline Tópicos de Eletromagnetismo & Psicologia aplic. à Educ. & Evolução do Pens. Cient. \\
\hline
\end{tabular}




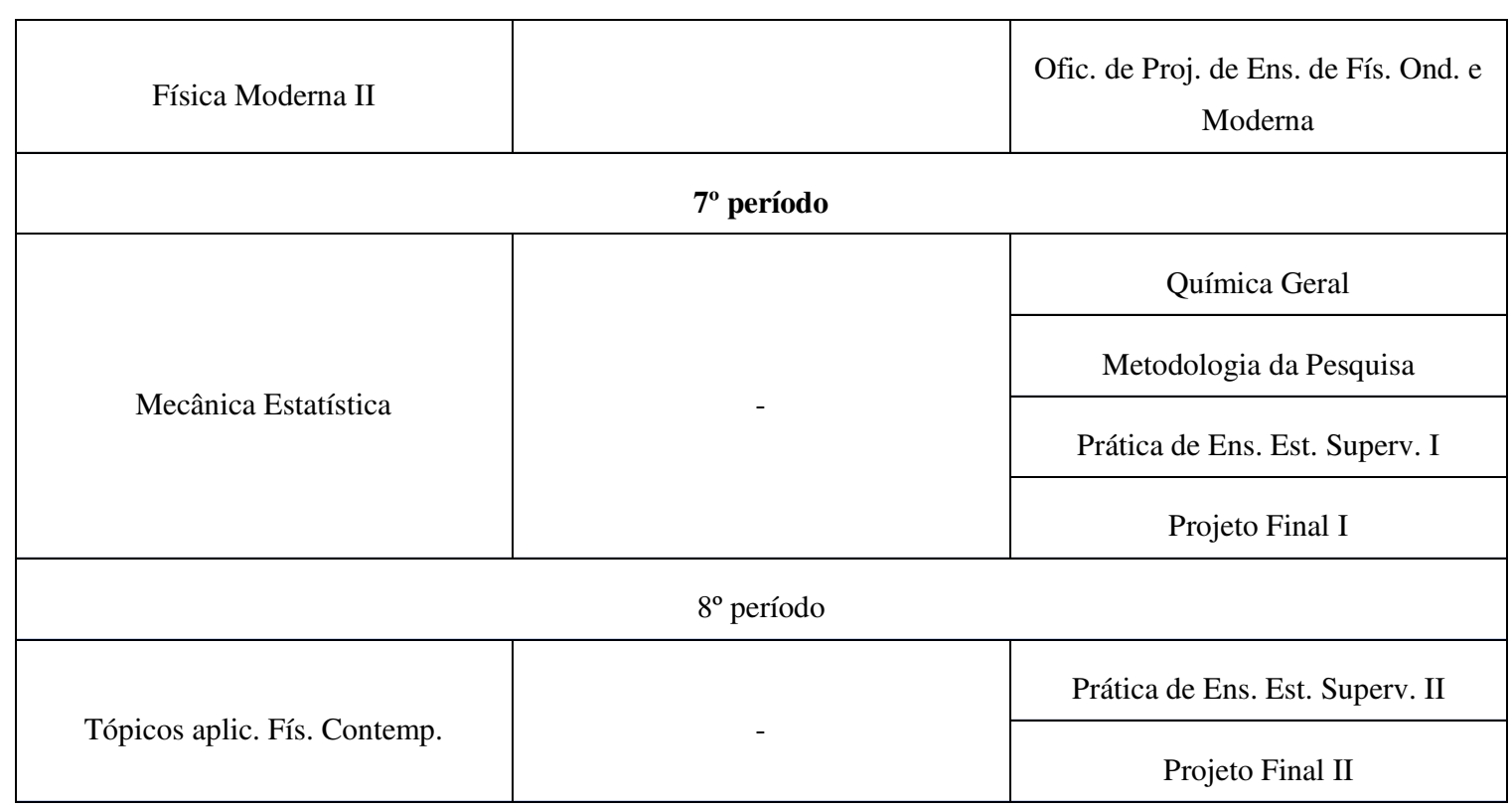

(c) EY-NC-ND Direito autoral e licença de uso: Este artigo está licenciado sob uma Licença Creative Commons. 